\title{
Development of cellobiose-degrading ability in Yarrowia lipolytica strain by overexpression of endogenous genes
}

Zhongpeng Guo ${ }^{1,2,3^{*}}$, Sophie Duquesne ${ }^{1,2,3}$, Sophie Bozonnet ${ }^{1,2,3}$, Gianluca Cioci ${ }^{1,2,3}$, Jean-Marc Nicaud ${ }^{4,5}$, Alain Marty ${ }^{1,2,3^{*}}$ and Michael Joseph $\mathrm{O}^{\prime}$ Donohue $\mathrm{e}^{1,2,3}$

\begin{abstract}
Background: Yarrowia lipolytica, one of the most widely studied "nonconventional" oleaginous yeast species, is unable to grow on cellobiose. Engineering cellobiose-degrading ability into this yeast is a vital step towards the development of cellulolytic biocatalysts suitable for consolidated bioprocessing.

Results: In the present work, we identified six genes encoding putative $\beta$-glucosidases in the Y. lipolytica genome. To study these, homologous expression was attempted in Y. lipolytica JMY1212 Zeta. Two strains overexpressing BGL 1 (YALIOF16027g) and BGL2 (YALIOB14289g) produced $\beta$-glucosidase activity and were able to degrade cellobiose, while the other four did not display any detectable activity. The two active $\beta$-glucosidases, one of which was mainly cell-associated while the other was present in the extracellular medium, were purified and characterized. The two Bgls were most active at $40-45^{\circ} \mathrm{C}$ and $\mathrm{pH} 4.0-4.5$, and exhibited hydrolytic activity on various $\beta$-glycoside substrates. Specifically, Bgl1 displayed 12.5-fold higher catalytic efficiency on cellobiose than Bgl2. Significantly, in experiments where cellobiose or cellulose (performed in the presence of a $\beta$-glucosidase-deficient commercial cellulase cocktail produced by Trichoderma reseei) was used as carbon source for aerobic cultivation, Y. lipolytica $\Delta$ pox co-expressing $B G L 1$ and $B G L 2$ grew better than the Y. lipolytica strains expressing single $B G L s$. The specific growth rate and biomass yield of Y. lipolytica JMY1212 co-expressing BGL1 and BGL2 were $0.15 \mathrm{~h}^{-1}$ and $0.50 \mathrm{~g}$-DCW/g-cellobiose, respectively, similar to that of the control grown on glucose.
\end{abstract}

Conclusions: We conclude that the bi-functional Y. lipolytica developed in the current study represents a vital step towards the creation of a cellulolytic yeast strain that can be used for lipid production from lignocellulosic biomass. When used in combination with commercial cellulolytic cocktails, this strain will no doubt reduce enzyme requirements and thus costs.

Keywords: Lignocellulosic biomass, Oleaginous yeast, Lipids, Enzymatic hydrolysis, Cellulases

\section{Background}

It is widely recognized that lignocellulosic biomass (or LC biomass) will form an important part of the future bioeconomy. However, the use of this renewable resource as feedstock for industrial activities poses a major challenge, because its deconstruction to sugars and lignin is complex, requiring a series of unit operations. These include

\footnotetext{
*Correspondence: zguo@insa-toulouse.fr; marty@insa-toulouse.fr ${ }^{1}$ LISBP-Biocatalysis Group, INSA/INRA UMR 792, Université de Toulouse, 135 Avenue de Rangueil, 31077 Toulouse, France

Full list of author information is available at the end of the article
}

costly pretreatment and enzymatic hydrolysis steps, the latter requiring the action of several types of enzymes $[1,2]$. Indeed, the hydrolysis of cellulose alone requires the synergistic action of endoglucanases (EC 3.2.1.4), cellobiohydrolases (EC 3.2.1.91) and $\beta$-glucosidases (EC 3.2.1.21) [3]. Endoglucanases are active on the internal bonds in cellulose and release free reducing and nonreducing extremities, which are used by cellobiohydrolases as starting points for exo-processive hydrolysis that yields cellodextrins as products. Finally, $\beta$-glucosidases convert cellodextrins into glucose [4]. 
One strategy to reduce investment and operational costs in LC biomass processing is to internalize enzyme production and combine enzymatic hydrolysis with fermentation. This is known as consolidated bioprocessing (CBP) and can be achieved using a microorganism that possesses the dual ability to produce biomass-hydrolyzing enzymes and ferment sugars to products of commercial interest, thus allowing a one-pot type bioconversion process in which process integration is maximized [5]. While CBP is considered to be an ultimate aim for biorefining, the ways to achieve this goal are not simple. Although the number of naturally occurring, biomassdegrading microorganisms is no doubt large, those that possess the ability to hydrolyze LC biomass and ferment free sugars into target products, such as ethanol, butanol, hydrogen, fatty acid ethyl esters (FAEE) or isopropanol, at industrially compatible rates and titers, are probably very rare and so far undiscovered [6]. Additionally, many of the best known biomass-degrading microorganisms display low $\beta$-glucosidase (cellobiase) activity, meaning that the hydrolysis of cellobiose constitutes a rate-limiting step during the enzymatic processing of cellulose [7-9]. Therefore, engineering cellobiose-degrading ability into microorganisms is a vital step towards the development of cellulolytic biocatalysts suitable for CBP. In this respect, examples of recent work performed on Saccharomyces cerevisiae, the current workhorse of biotechnological processes, are noteworthy [10-12]. In these studies, even though the engineered S. cerevisiae strains exhibited poor cellulose-degrading ability, the fact that they both produce significant cellobiase activity means that their incorporation into a simultaneous saccharification and fermentation (SSF) process is likely to reduce the loading of external cellulases and thus overall process cost [10].

Although ethanol is the target molecule in many biorefinery concepts, Fatty Acid Esters (FAEs) such as those used in biodiesel, are also attractive targets. This is because FAEs display high energy density and are welltolerated by production strains [13]. Currently, FAEs are mainly produced by transesterification of plant oils using an alcohol (methanol or ethanol) and base, acid or enzyme catalysts [14]. However, the high cost of this process and various issues surrounding the production of plant oils for non-food purposes make the search for alternative routes both attractive and strategically pertinent. In this respect, microbial production of biofuels (so-called microdiesel and microkerosene) represents a sustainable and quite economical way to produce FAEs. For this purpose, both Escherichia coli and S. cerevisiae have been engineered to produce structurally tailored fatty esters [15-17]. However, neither of these microorganisms is naturally able to accumulate high amounts of lipids, nor able to degrade cellulose. Moreover, in these microorganisms the biosynthesis of fatty acid is highly regulated [18], thus limiting the possibility to improve lipid production $[16,17,19]$.

So-called oleaginous microorganisms, which naturally accumulate lipids to more than $20 \%$ of their dry cell weight (DCW) [20, 21], have already been exploited for the production of commercially useful lipids, such as substitutes for cocoa butter and polyunsaturated fatty acids [22]. Therefore, it is unsurprising that microbial lipid or single cell oil is also being considered for biodiesel production, especially because this route implies shorter production times, reduced labor costs and simpler scale-up [23]. Prominent among the oleaginous microorganisms, Yarrowia lipolytica has been extensively studied and is known to accumulate lipids up to $50 \%$ of its dry weight depending on culture conditions [20, 21, 24]. Advantageously, since Y. lipolytica is already widely used in the detergent, food, pharmaceutical and environmental industries it has been classified by the FDA (Food and Drug Administration) as "Generally Recognized as Safe" (GRAS) for numerous processes [25]. Nevertheless, despite these advantages, Y. lipolytica displays limited ability for sugar use and is unable to use cellulose as carbon source [26].

In a recent paper, the use of cellobiose by $Y$. lipolytica was tackled for the first time, thus opening the way towards the development of an efficient yeast-based CBP microorganism capable of consuming cellulosederived glucose and converting it into lipids and derivatives thereof [27]. Herein, we present work that shares this aim, but which has employed a different strategy that relies upon the activation of endogenous $\beta$-glucosidase activity (Fig. 1).

\section{Results}

Identification of genes encoding active $\beta$-glucosidases in Y. lipolytica

Analysis of the $Y$. lipolytica genome using BLAST revealed the presence of six sequences that were identified as putative family GH3 $\beta$-glucosidases (see Additional file 1: Table S1; Additional file 2: Fig. S1) on the basis of high amino acid sequence identity with other yeast $\beta$-glucosidases (Fig. 2, Additional file 2: Fig. S1). However, in the absence of biochemical data it was impossible to assert at this stage that these sequences actually encode $\beta$-glucosidases, since family GH3 contains glycoside hydrolases that display other specificities. Moreover, Y. lipolytica does not grow on cellobiose and has not been found to express a detectable level of $\beta$-glucosidase activity (Additional file 2: Fig. S2), despite the fact that preliminary transcriptional analysis revealed that the six genes are weakly transcribed when $Y$. 


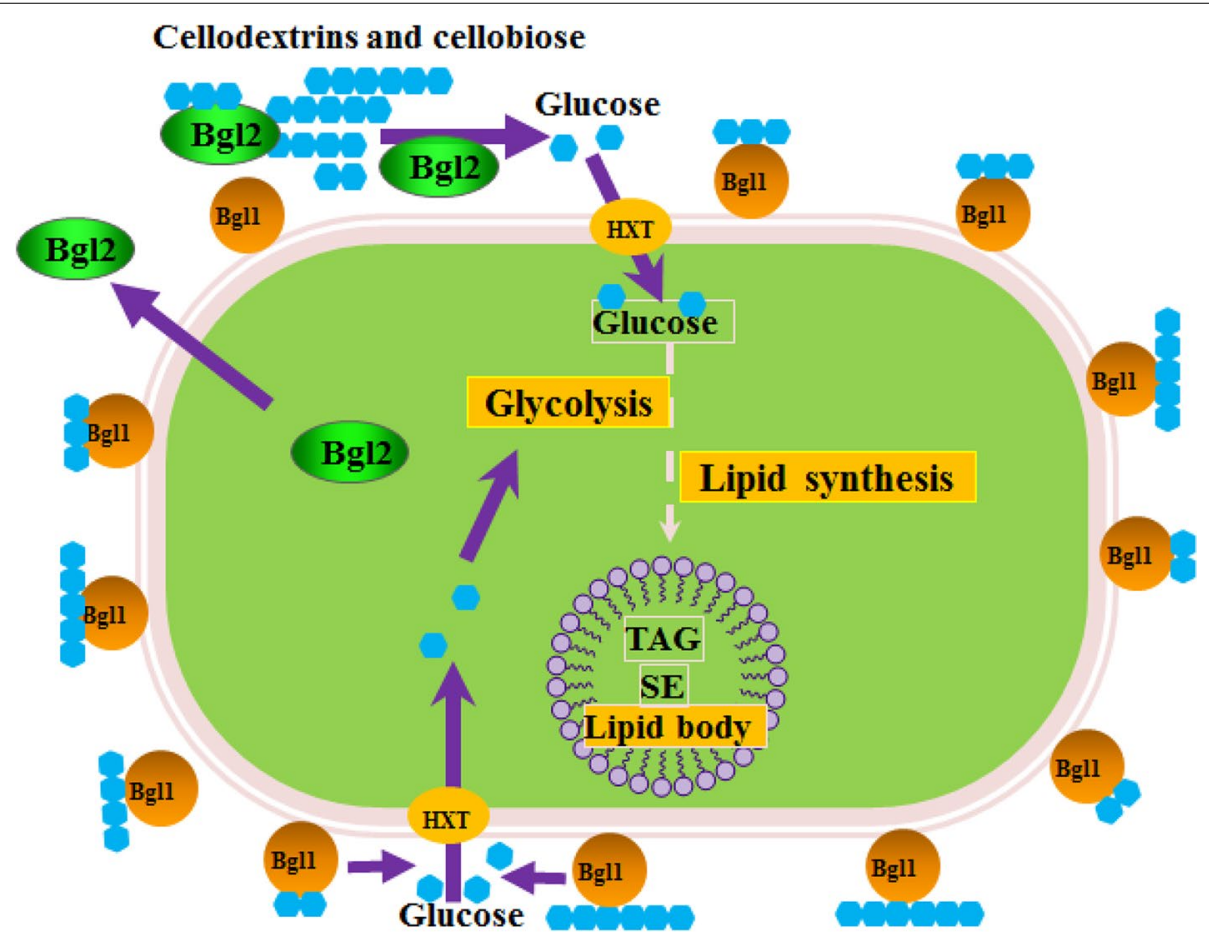

Fig. 1 The strategies used in the current study to develop the cellobiose-degrading ability in Y. lipolytica.

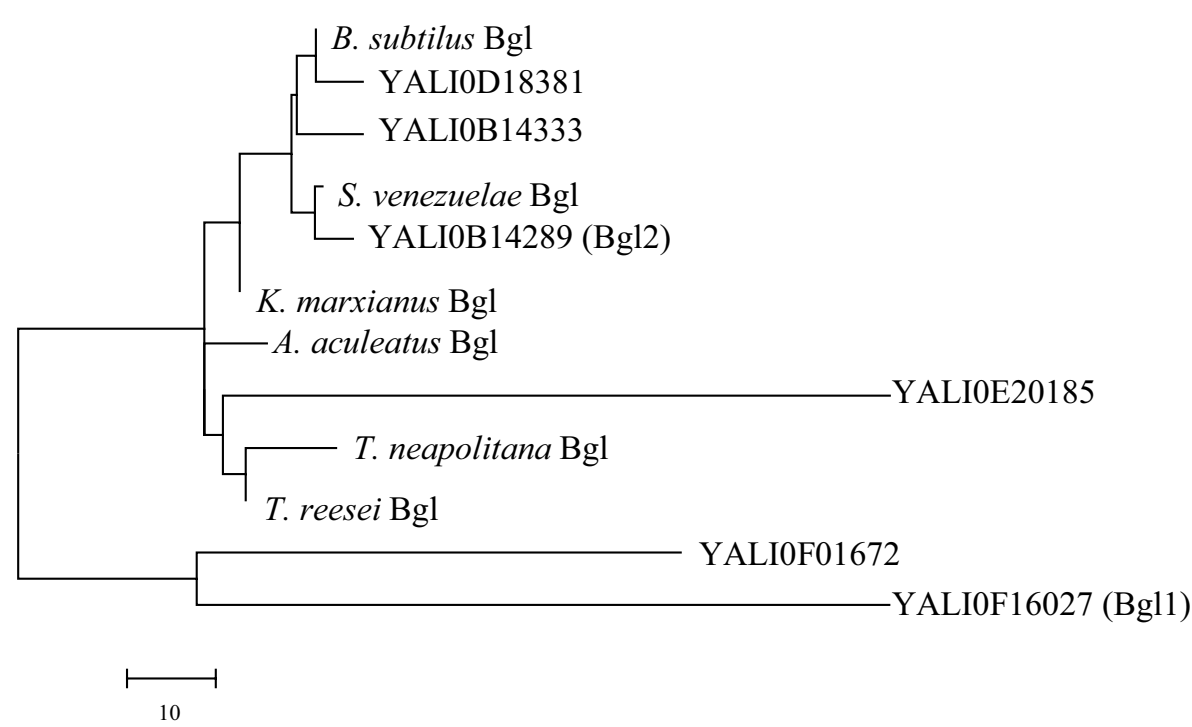

Fig. 2 Phylogenetic tree of the structurally characterized family three glycosyl hydrolases. Multiple-sequence alignment was performed using CLUSTALW (http://www.genome.jp/tools/clustalw/), and a phylogenetic tree was constructed using MEGA5 (http://www.megasoftware.net/). Sequences are: Bacillus subtilus Bgl (PDB accession number 4GYJ_A); Streptomyces venezuelae Bgl (PDB accession number 4I3G_A); Kluyveromyces marxianus Bgl (PDB accession number 3ACO_A); Aspergillus aculeatus Bgl (PDB accession number 4III_A); Thermotoga neapolitana Bgl (PDB accession number 2X42_A); Trichoderma reesei Bgl (PDB accession number 4l8D_A); and include the 6 putative GH3 sequences from Yarrowia lipolytica genome.

lipolytica is grown on glucose, although no further induction was observed in the presence of cellobiose (Additional file 2: Fig. S3). In this respect, it was particularly gratifying to observe that overexpression of $B G L 1$ (YALIOF16027g) or BGL2 (YALIOB14289g) in Y. lipolytica (strains ZetaB 1 and ZetaB 2, respectively) enhanced 
the transcription of the genes and conferred the ability to grow on solid medium containing cellobiose as the sole carbon source (Additional file 2: Figs. S2, 3). Additionally, when these recombinant strains were grown on YNB- $p$ NP- $\beta$ Glc $\quad(p$-nitrophenyl- $\beta$-D-glucoside) plates, yellow halos surrounding the colonies were clearly visualized, indicating $\beta$-glucosidase activity (Additional file 2 : Fig. S3). Finally, after growth in liquid YTD medium, $\beta$-glucosidase activity could be measured in the cell extract of ZetaB $1(3.2 \pm 0.2 \mathrm{IU} / \mathrm{mg})$ and in the culture supernatant of ZetaB $2(2.6 \pm 0.1 \mathrm{U} / \mathrm{mL})$, while much lower activities were measured in the culture supernatant of ZetaB $1(0.33 \pm 0.02 \mathrm{U} / \mathrm{mL})$ and in the cell extract of ZetaB $2(0.42 \pm 0.01 \mathrm{IU} / \mathrm{mg})$. Regarding the remaining four putative $\beta$-glucosidases, expression of their encoding sequences (YALIOF01672g, YALIOD18381g, YALIOB14333g and YALIOE20185g) in Y. lipolytica failed to produce any detectable $\beta$-glucosidase activity or sustain yeast growth on solid medium containing cellobiose as the sole carbon source.

To further investigate the production of the six $\beta$-glucosidases, western blot analysis was carried out using anti-His6 antibodies. This revealed the presence of Bgl1-His6 in both the culture supernatant and cell extract (Fig. 3a, b). Bgl2-His6 could only be detected in concentrated (tenfold) cell extract (Fig. 3c). However, this method failed to detect Bgl2-His6 in the culture media
(Fig. 3d), consistent with the fact that no $\beta$-glucosidase activity was detected in this fraction. Significantly, the expression of the native $B G L 2$ sequence (i.e. without the His6-tag) provided much more satisfactory expression, implying that the presence of the His6-tag on Bgl2 somehow impairs the expression and/or secretion of this protein.

\section{Localization of $\beta$-glucosidases in ZetaB 1 and ZetaB 2}

To determine the localization of Bgl1 and Bgl2, yeast cells producing these enzymes (without His6 tag) were fractionated, generating on the one hand extracellular samples (culture supernatant), and on the other cellassociated periplasmic, cytoplasmic and membrane fractions. Measurement of the $\beta$-glucosidase activities in each of these fractions revealed that Bgl1 was primarily localized in the periplasm (61\%), but was also present in the cytoplasm (30\%), while Bgl2 was mainly in the supernatant $(80 \%)$, and to a lesser extent $(26 \%)$ in the periplasm (Table 1). The apparent ambiguity of these results is undoubtedly due to the separation method that was employed to isolate the different cellular fractions, which inevitably led to a low level of cross-contamination between the samples. Nevertheless, taking this into account, it is reasonable to deduce that Bgl1 is primarily localized in the periplasmic space, while Bgl2 is secreted into the culture medium.

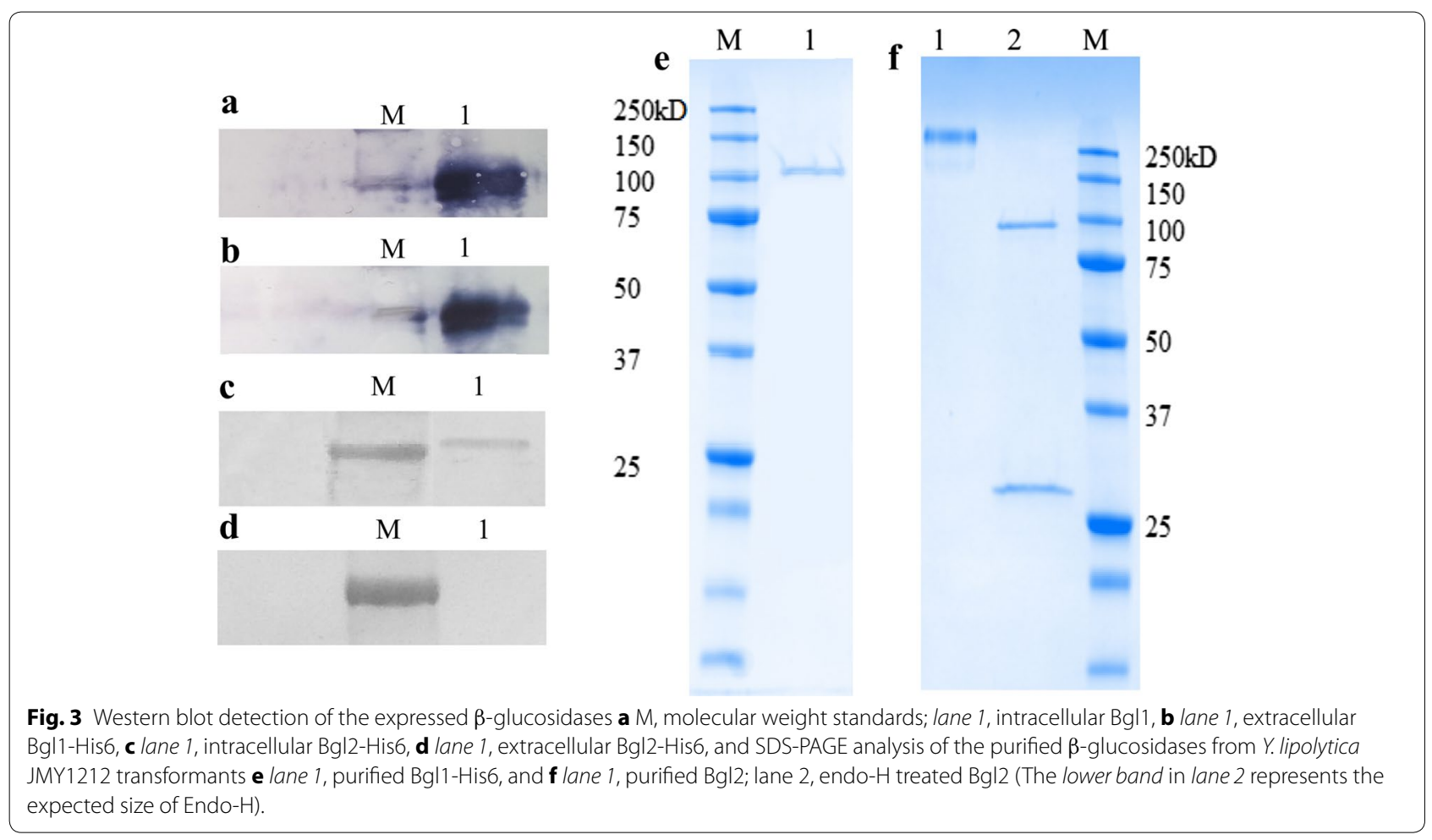


Table 1 Distribution of $\beta$-glucosidase activity in recombinant strains ZetaB 1 and ZetaB 2

\begin{tabular}{lll}
\hline Fraction & \multicolumn{2}{l}{ Relative enzyme activity } \\
\cline { 2 - 3 } & Bgl1 (\%) & Bgl2 (\%) \\
\hline Total & 100 & 100 \\
Growth medium & $2.3 \pm 0.4$ & $79.6 \pm 1.2$ \\
Periplasm & $60.7 \pm 1.0$ & $25.8 \pm 1.0$ \\
Cytoplasm & $30.0 \pm 0.5$ & $4.8 \pm 0.8$ \\
Membrane & $8.1 \pm 0.7$ & $3.7 \pm 0.3$ \\
\hline
\end{tabular}

\pm , the standard deviation.

${ }^{a}$ Triplicate experiments. Activity was assayed with pNP- $\beta$ Glc.

\section{Production, purification and characterization of Bgl1 and Bgl2}

Production of Bgl1-His6 and native Bgl2 was achieved by growing the appropriate $Y$. lipolytica strains on YTD, with expression of both enzymes increasing until complete depletion of glucose was reached (36 h).

Regarding purification of Bgl1-His6, yeast cells from a 200-mL culture volume yielded approximately $550 \mathrm{U}$ of enzyme in the crude cell extract. However, after one step of affinity-purification, only $17 \%$ of Bgl1 was recovered (Table 2). In the case of Bgl2, a two-step protocol using anion exchange chromatography and gel filtration allowed its purification to near homogeneity, but led to significant loss of protein (8.8\% recovery). SDS-PAGE analysis of the two purified protein samples revealed that while the $M_{\mathrm{r}}$ of Bgl1 was consistent with the expected value (i.e. $M_{\mathrm{r}}$ of $90.4 \mathrm{kDa}$ for the protein lacking the putative signal peptide), that of Bgl2 was significantly higher (>250 kDa) (Fig. 3e, f). To investigate whether this discrepancy was due to glycosylation, the amino acid sequence of Bgl2 was analyzed using the glycosylation predictor GlycoEP (http://www.imtech.res.in/ raghava/glycoep/) [28]. This revealed that Bgl2 harbors 18 potential $\mathrm{N}$-glycosylation sites (Additional file 1: Table S2). Glycosylation was finally confirmed by treating the purified Bgl2 protein with endoglycosidase $\mathrm{H}$ (EndoH) and migrating it on a SDS-PAGE. This analysis revealed that the $M_{\mathrm{r}}$ of the recombinant EndoH-treated $\mathrm{Bgl} 2$ was approximately $95 \mathrm{kDa}$, quite consistent with the theoretical $\mathrm{Mr}$ of $92.9 \mathrm{kDa}$ (Fig. 3f). Finally, N-terminal amino acid sequence analysis of Bgl1 and Bgl2 confirmed that the signal sequences of both proteins had been cleaved and allowed the accurate localization of the cleavage sites (Additional file 2: Fig. S4).

Preliminary characterization of Bgl1 and Bgl2 using $p$ NP- $\beta$ Glc as substrate revealed that Bgl1 was 5 -fold more active $(102.8 \mathrm{U} / \mathrm{mg})$ on this substrate than Bgl2 (25.8 U/ $\mathrm{mg})$. The activity of Bgl1 was highest at approximately $\mathrm{pH}$ 4.5 and $45^{\circ} \mathrm{C}$, and was stable in the $\mathrm{pH}$ range of 4.0-5.0 and below $40^{\circ} \mathrm{C}$. Regarding Bgl2, it was found to display highest activity at $\mathrm{pH} 4.0$ and $50^{\circ} \mathrm{C}$ and was stable in the $\mathrm{pH}$ range of $3.5-7.0$ and below $50^{\circ} \mathrm{C}$ (Additional file 2: Figs. S5, S6). It is noteworthy that deglycosylation of Bgl2 led to a $60 \%$ decrease in specific activity, which was probably due to its instability at $40^{\circ} \mathrm{C}$ (Additional file 2: Fig. S7).

\section{Substrate specificity and kinetic parameters of Bgl1 and Bgl2}

The substrate specificity of the purified $\beta$-glucosidases was examined using different substrates displaying $\alpha$ and $\beta$ configurations. The results showed that both $\beta$-glucosidases were maximally active against $p \mathrm{NP}$ $\beta$ Glc (Fig. 4). However, using activity on $p$ NP- $\beta$ Glc as benchmark, it is noteworthy that both enzymes were active on $p$ NP- $\beta$-D-cellobioside (Bgl1, 24\% and Bgl2, 27\%), but only Bgl1 displayed significant activity $(10 \%)$ on $p$ NP- $\beta$-D-xylopyranoside. Neither enzyme displayed activity on $p$ NP- $\beta$-D-galactopyranoside and $p \mathrm{NP}-\alpha$-D-glucopyranoside.

When the activity of Bgl1 and Bgl2 on cellobiose was compared with that on other oligosaccharides, it was found that both enzymes displayed highest activity on laminaribiose $(\beta-1,3$-linkage), followed by gentiobiose

Table 2 Purification of intracellular Bgl1-His6 and extracellular Bgl2 produced by Y. lipolytica overexpressing strains

\begin{tabular}{lcclcc}
\hline Enzyme and purification method & Total protein $(\mathbf{m g})$ & Total activity $(\mathbf{U})$ & Specific activity $(\mathbf{U} / \mathbf{m g})$ & Fold purification & Yield (\%) recovery \\
\hline Bgl1-His6 & & & & - & 100 \\
$\quad$ Filtrate & 169.7 & 543.0 & - & 32.1 & 17.0 \\
TALON His-tag & 0.9 & & 102.8 & - & 100 \\
Bgl2 & & 530.2 & - & 1.1 & 96.3 \\
Culture supernatant & 2302.5 & 510.5 & - & 7.7 & 90.2 \\
Ultra filtration & 1986.4 & 478.5 & - & 112.2 & 8.8 \\
lon exchange & 235.3 & 46.4 & 25.8 & & \\
Gel filtration & 1.8 & &
\end{tabular}

a Specific activity was tested on pNP- $\beta$ Glc. 

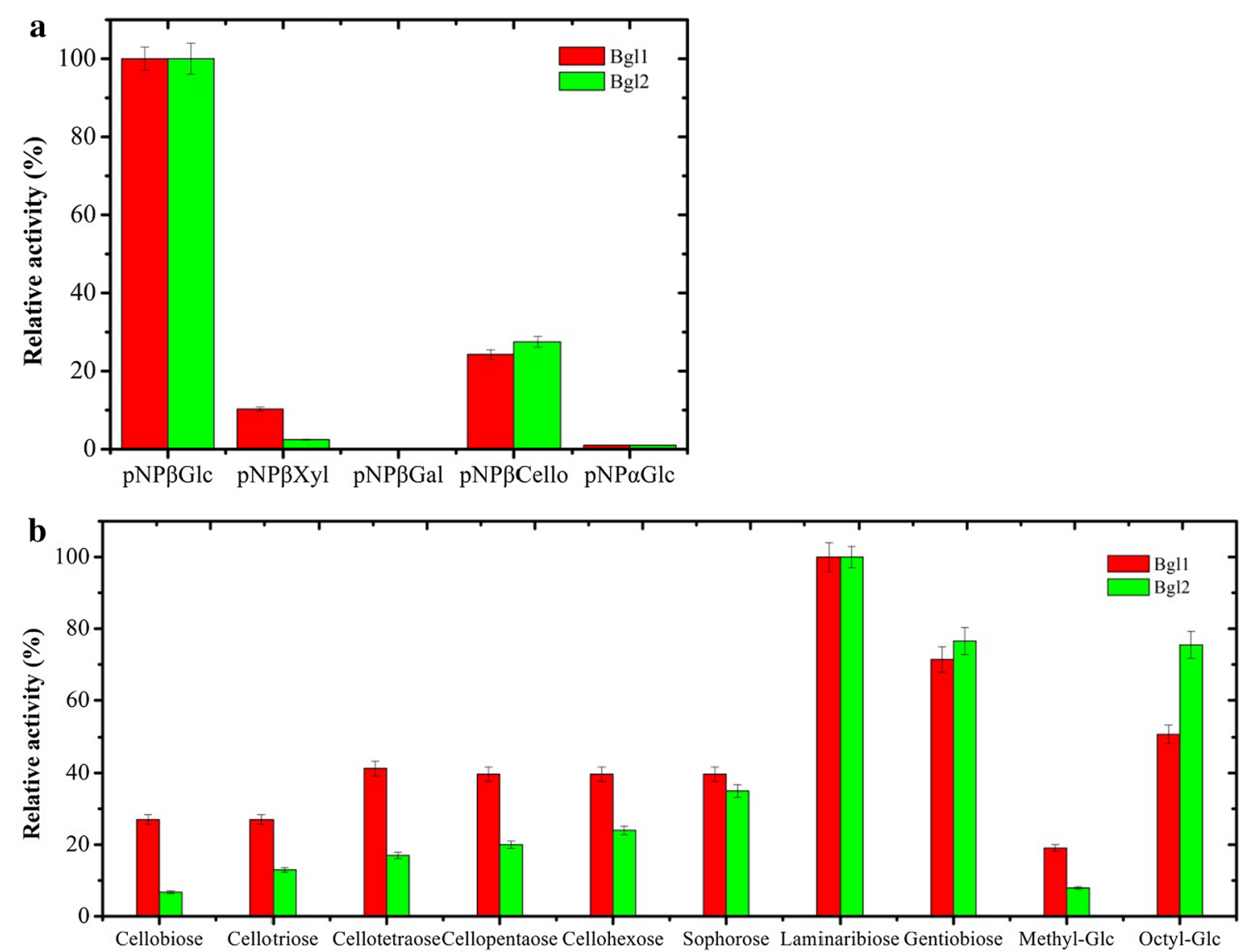

Fig. 4 Comparison of the hydrolytic activity of $\beta$-glucosidases from Y. lipolytica JMY1212. Bgl1-His and Bgl2 on a pNP-derived substrates, and $\mathbf{b}$ natural glycosyl substrates with different $\beta$-configurations.

( $\beta$-1, 6-linkage), octylglucoside, sophorose $(\beta-1,2$-linkage), cello-oligosaccharides ( $\beta-1,4$-linkage, trisaccharide and higher)) and cellobiose ( $\beta-1,4$-linkage). It is noteworthy that the hydrolytic activity of Bgl1 was less dependent on the chain length of cello-oligosaccharides, while hydrolytic activity of Bgl2 increased as the length of cello-oligosaccharides increased. Both enzymes recognized methylglucoside as substrate, but the hydrolytic activities were low compared with the other substrates (Fig. 4), indicating that correct occupation of subsite +1 is important for catalysis.

The determination of the apparent kinetic parameters of reactions catalyzed by Bgl1 and Bgl2 and containing various glucosyl disaccharides and cello-oligosaccharides revealed that the values of $K_{\mathrm{M}}(\mathrm{app})$ and $k_{\text {cat }} / K_{\mathrm{M}}$ for Bgl2catalyzed reactions increased as a function of degree of polymerization (DP) of the cello-oligosaccharides (Table 3). In the case of Bgl1, increased DP was associated with increased $K_{\mathrm{M}}(\mathrm{app})$ values, but not $k_{c a t} / K_{\mathrm{M}}$ values. Overall, considering the performance constant $\left(k_{c a t} / K_{\mathrm{M}}\right)$, cellobiose and cellohexaose were the best substrates for Bgl1 and Bgl2, respectively. Additionally, the performance constant of Bgl1 measured on cellobiose was 12.5-fold higher than that describing Bgl2. Regarding other glucosyl substrates (i.e. those containing linkages other than $\beta-1,4)$, both Bgls displayed the highest performance constants on laminaribiose. Nevertheless, comparison of the performance constants on each of the substrates revealed that $\mathrm{Bgl} 2$ is less regioselective, since the $k_{\text {cat }} / K_{\mathrm{M}}$ values were always lower in reactions catalyzed by Bgl1 (86\% for sophorose, $47 \%$ for laminaribiose, $37 \%$ for gentiobiose, $18 \%$ for methylglucoside and $45 \%$ for octylglucoside). Finally, the lowest performance constants for both Bgls were measured for reactions containing methylglucoside.

\section{Cellobiose and cello-oligosaccharide fermentation with $Y$. lipolytica recombinant strains}

Yeast strains ZetaB 1 and ZetaB 2, expressing BGL1 and $B G L 2$, respectively, were grown in micro cultivation plates under aerobic conditions in the presence of cellobiose or cellodextrins (until Glc $\times 6$ ) as sole carbon sources, using 
Table 3 Kinetic parameters of Y. lipolytica Bgls for various glycoside-substrates

\begin{tabular}{|c|c|c|c|c|c|c|c|}
\hline \multirow[t]{2}{*}{ Substrate } & \multirow[t]{2}{*}{ Linkage } & \multicolumn{3}{|l|}{ Bgl1 } & \multicolumn{3}{|l|}{$\mathrm{Bgl2}$} \\
\hline & & $K_{\mathrm{M}}(\mathrm{mM})$ & $k_{\text {cat }}\left(\mathrm{s}^{-1}\right)$ & $k_{\text {cat }} / K_{\mathrm{M}}\left(\mathrm{mM}^{-1} \mathrm{~s}^{-1}\right)$ & $K_{\mathrm{M}}(\mathrm{mM})$ & $k_{\text {cat }}\left(\mathrm{s}^{-1}\right)$ & $k_{c a t} / K_{\mathrm{M}}\left(\mathrm{mM}^{-1} \mathrm{~s}^{-1}\right)$ \\
\hline Cellobiose & $\mathrm{Glc} \times 2, \beta-\mathrm{I}, 4$ & 0.26 & 21.1 & 81.1 & 0.79 & 5.1 & 6.5 \\
\hline Cellotriose & $\mathrm{Glc} \times 3, \beta-1,4$ & 0.43 & 20.5 & 47.7 & 0.99 & 9.5 & 9.6 \\
\hline Cellotetraose & Glc $\times 4, \beta-1,4$ & 1.89 & 30.9 & 16.3 & 1.86 & 20.6 & 11 \\
\hline Cellopentaose & Glc $\times 5, \beta-1,4$ & 2.18 & 29.5 & 13.5 & 2.24 & 27.5 & 12.3 \\
\hline Cellohexaose & Glc $\times 6, \beta-1,4$ & 3.01 & 31.5 & 10.5 & 2.37 & 30.5 & 12.9 \\
\hline Sophorose & Glc $\times 2, \beta-1,2$ & 2.25 & 28.4 & 14.8 & 2.4 & 41.2 & 17.2 \\
\hline Laminaribiose & Glc $\times 2, \beta-1,3$ & 0.68 & 75.6 & 110.7 & 0.89 & 211.1 & 237.2 \\
\hline Gentiobiose & $\mathrm{Glc} \times 2, \beta-1,6$ & 1.16 & 43.6 & 37.6 & 1.84 & 186.5 & 101.4 \\
\hline Methylglucoside & $C=1$ & 15 & 15 & 1 & 6.23 & 34.1 & 5.5 \\
\hline Octylglucoside & $C=8$ & 0.86 & 32.8 & 38.1 & 1.3 & 111.1 & 85.2 \\
\hline
\end{tabular}

The mean values of three independent experiments are shown and the standard deviation is below $10 \%$. Hydrolytic activities for the substrate were determined from the amount of released glucose and the kinetic parameters were calculated as described in "Methods".

wild-type $Y$. lipolytica ZetaW as the control. The maximum specific growth rates $\left(\mu_{\max }\right)$ of the transformants on cellobiose were essentially the same as that of the control grown on glucose (Fig. 5a, b). ZetaB 1 grew faster than ZetaB 2 on cellobiose and cellodextrins (Fig. 5b-f), while the control was unable to grow on either of these substrates. Surprisingly, despite indications that the wildtype strain cannot grow on cellobiose or cellodextrins, the control culture (ZetaW) reached an OD value of 2.0. However, further investigation using a defined medium revealed that this unexpected growth could be attributed to the presence in the medium of $0.2 \% \mathrm{w} / \mathrm{v}$ casamino acids, which acted as a suitable carbon source. In defined medium, ZetaB 1 consumed $80 \%$ cellobiose over $48 \mathrm{~h}$. However, upon further incubation, the remaining $20 \%$ cellobiose (at the concentration of $2 \mathrm{~g} / \mathrm{L}$ ) was not consumed (Fig. 6). In contrast, ZetaB 2 consumed all of the cellobiose over 60 h. Furthermore, ZetaB 1 sustained a specific growth rate $\left(\mu_{\max }\right)$ of $0.10 \mathrm{~h}^{-1}$, whereas ZetaB 2 exhibited a long lag phase on cellobiose after which two subsequent growth phases ( $\mu_{\max }$ values of $0.08 \mathrm{~h}^{-1}$ and then $0.16 \mathrm{~h}^{-1}$ ) were observed (Fig. 6; Table 4). In order to combine the advantages procured by the overexpression of BGL1 and $B G L 2$ (i.e. shorter lag phase and higher cellobiose utilization, respectively), the two $B G L$ sequences were cloned into JMY1212, thus yielding ZetaB 12. During cultivation on cellobiose, the performance of ZetaB 12 was the best among all the recombinant strains. It showed similar growth rate to that of the control grown on glucose and consumed $10 \mathrm{~g} / \mathrm{L}$ of cellobiose within $40 \mathrm{~h}$.

\section{Characterization of cellulose-based lipid production by recombinant $Y$. lipolytica strains}

To investigate whether the BGLs described in this study could be used to construct a lipid-producing strain, a previously described strategy to increase lipid accumulation, involving the deletion of the $6 P O X$ genes $(P O X 1$ to $P O X 6)$ that encode the peroxisomal acyl-coenzyme oxidases involved in lipid $\beta$-oxydation, was adopted [29]. Accordingly, $Y$. lipolytica $\Delta p o x \mathrm{~B} 1, \Delta p o x \mathrm{~B} 2$ and $\Delta p o x \mathrm{~B} 12$ were constructed and grown on cellulose in the presence of Celluclast 1.5L. Even though this cocktail is reputedly $\beta$-glucosidase-deficient, to avoid any problems (i.e. spurious results linked to the presence of $\beta$-glucosidase in Celluclast) the Celluclast loading was kept low (7.5 FPU/g cellulose), and control experiments containing the prototrophic $Y$. lipolytica $\Delta$ pox $\mathrm{W}$ strain grown in the presence of Celluclast $1.5 \mathrm{~L}$ with or without $\beta$-glucosidase supplementation were performed. During the initial $6 \mathrm{~h}$ of cultivation an accumulation of reducing sugars was observed in all of the cultures, which was attributed to Celluclast 1.5L-mediated cellulose hydrolysis. However, further monitoring revealed that after 12-h growth, less reducing sugars were present in the $Y$. lipolytica $\Delta p o x \mathrm{~B} 12 \mathrm{cul}-$ ture $(2.7 \mathrm{~g} / \mathrm{L})$ compared to the other cultures (Fig. $7 \mathrm{a})$. Moreover, this observation was correlated with continued yeast growth, whereas the growth of the other cultures stagnated over the same period (Fig. 7b). After $60 \mathrm{~h}$ of cultivation, the growth of $\triangle p o x \mathrm{~B} 12$ reached a stationary phase. At this point the amount of FAMEs obtained after the methylation of Total fatty acids produced by this yeast had reached $0.8 \mathrm{~g} / \mathrm{L}$ (Fig. 7c), but further growth did not result in an increase in cellular lipid content, reflecting a limitation of the available energy source. Besides the longer lag phase, the growth of $\Delta p o x \mathrm{~B} 1$ and $\Delta p o x \mathrm{~B} 2$ was similar to that of the control culture supplemented with $\beta$-glucosidase. Regarding the control culture, in the absence of $\beta$-glucosidase supplementation, growth ceased after $60 \mathrm{~h}$ and the cell density of the culture was approximately half that of the other cultures. Moreover, 


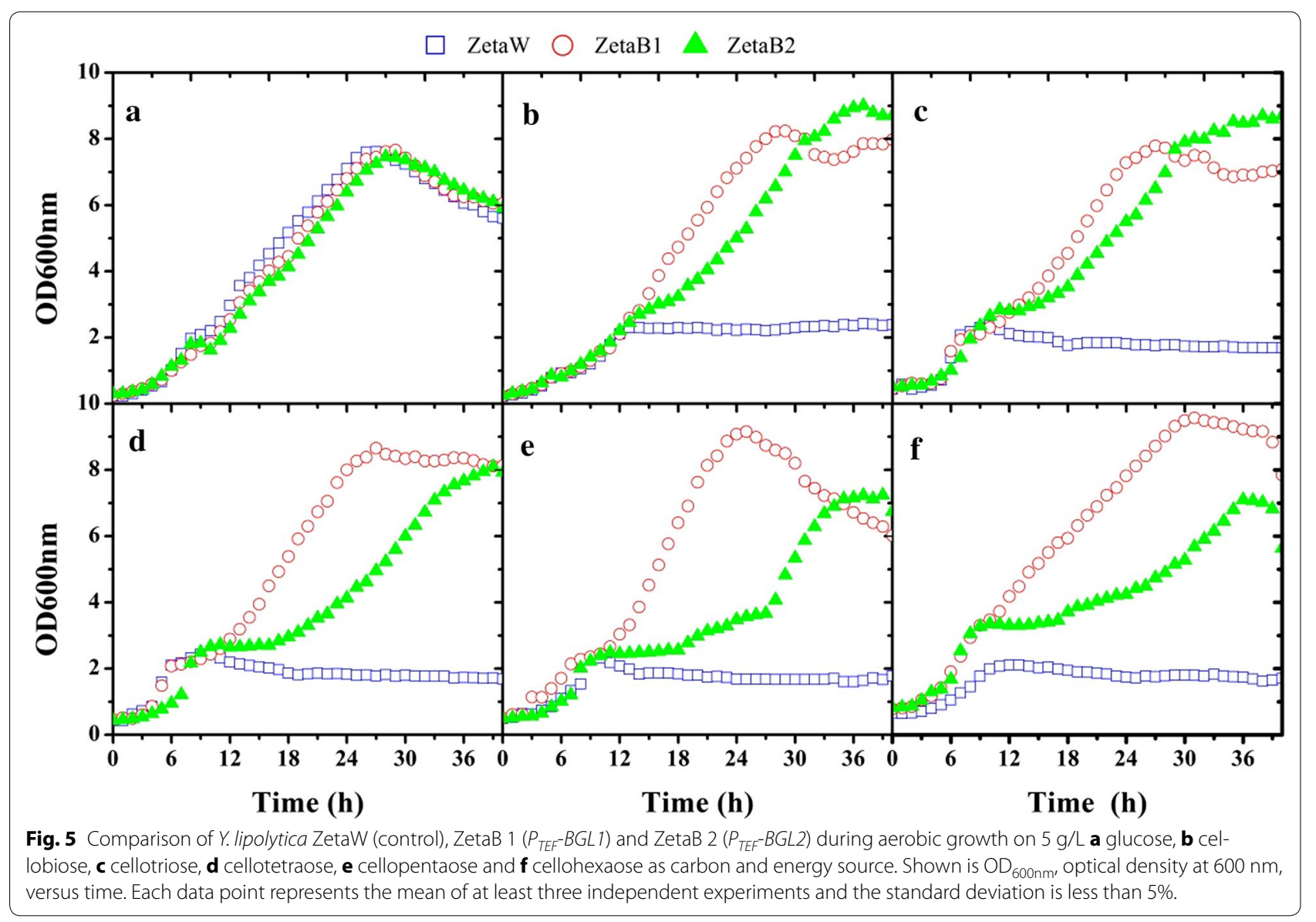

continuous addition of cellulases to the control culture did not procure any obvious increase in growth. When the control was supplemented with $\beta$-glucosidase, the amount of cellulose that remained unconsumed $(25 \mathrm{~g} / \mathrm{L})$ was similar to that of cultures of the $\Delta p o x$ strain expressing $\beta$-glucosidases after 5 days of growth.

\section{Discussion}

Even though fungal $\beta$-glucosidases can be produced at relatively low cost via solid-state fermentation [30], cellulases still account for almost $50 \%$ of the cost of cellulose hydrolysis processes [31]. Moreover, taking into account the fact that the $T$. reesei secretome is rather deficient in $\beta$-glucosidases, it is particularly relevant to engineer microorganisms that are self-sufficient with regard to this type of enzyme activity.

To date, S. cerevisiae has been the main target for engineering aimed at the creation of a cellulolytic yeast strain for consolidated bioprocessing purposes [32, 33]. However, Y. lipolytica is one of the most widely studied "non conventional" oleaginous yeast species, which is well characterized for its ability to use hydrophobic substrates (e.g. alkanes, FAs, oils), glucose and glycerol as carbon sources for the production of lipids [34]. Nevertheless, $Y$. lipolytica is also known for its inability to grow on cellulose or even cellobiose. Therefore, it also constitutes an attractive target for strain engineering work.

Interestingly, comparative genomics has revealed that $Y$. lipolytica is only distantly related to the majority of yeast species and instead shares a number of common properties with filamentous fungi [35]. Therefore, based on this observation, we investigated whether Y. lipol$y$ tica harbors genes that allow cellobiose degradation and thus the possibility to confer cellobiose-degrading ability to $Y$. lipolytica through the use of endogenous $\beta$-glucosidases. Gratifyingly, our data clearly revealed that at least two genes, designated $B G L 1$ and $B G L 2$, encode $\beta$-glycosidases, active under the control of TEF promoter, that hydrolyze cellobiose, although our results also indicate that these enzymes do not exclusively cleave $\beta-1,4$ linkages. In this respect, it is noteworthy that many cellobiolytic yeasts, such as Debaryomyces vanrijiae [36], Candida peltata [37], Monascus purpureus [38], Kluyveromyces fragilis [39] and Metschnikowia pulcherrima [40], only produce one active $\mathrm{Bgl}$ and even in the case of S. fibuligera, which produces two active Bgls, only 

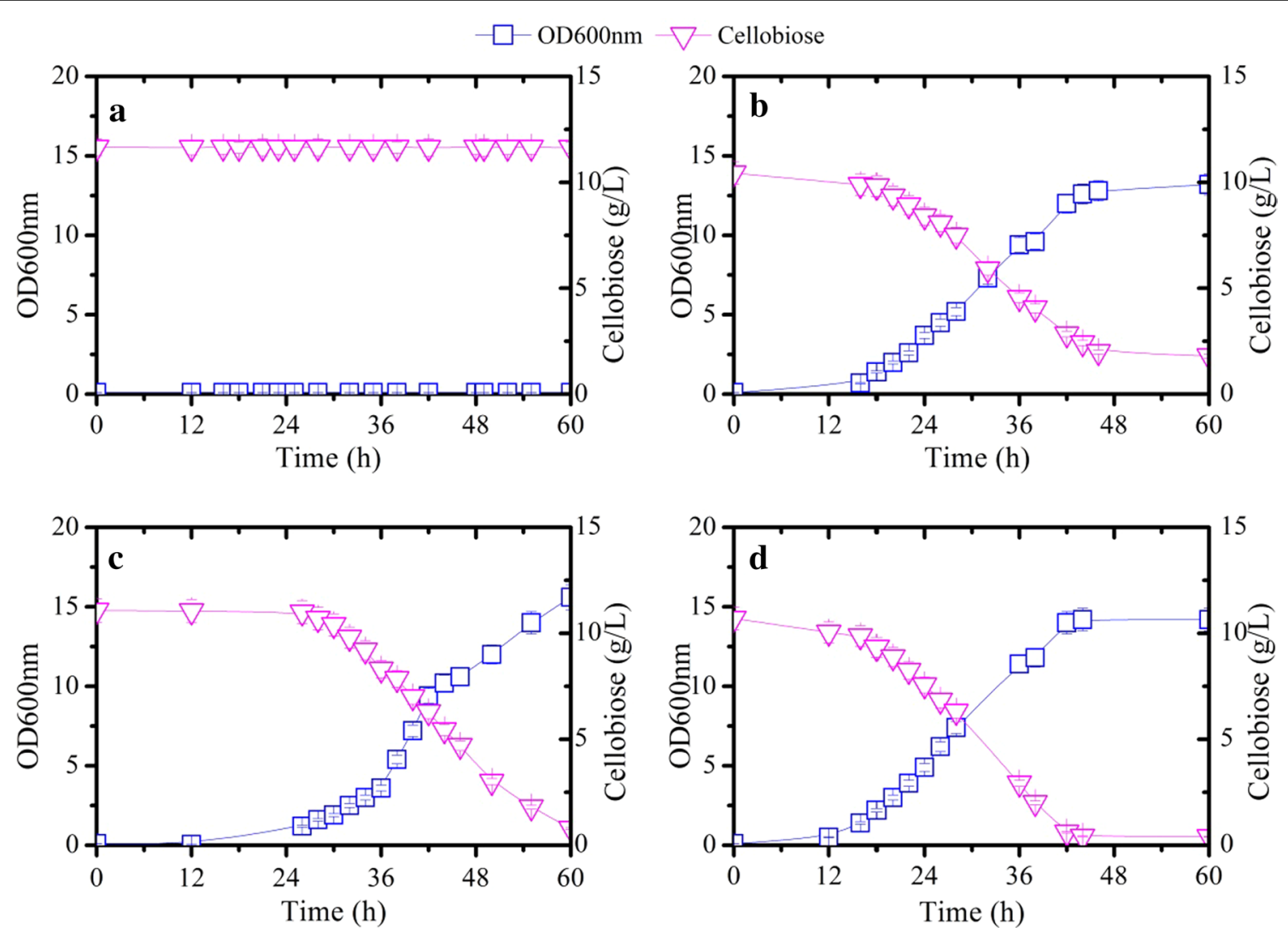

Fig. 6 Comparison of Y. lipolytica a ZetaW (control), b ZetaB $1\left(P_{\text {TEF }}-B G L 1\right)$, c ZetaB $2\left(P_{\text {TEF }}-B G L 2\right)$ and $\mathbf{d}$ Zeta-B12 $\left(P_{\text {TEF }}-B G L 1, P_{\text {TEF }}-B G L 2\right)$ during aerobic growth on $10 \mathrm{~g} / \mathrm{L}$ cellobiose. Shown are $\mathrm{OD}_{600 \mathrm{~nm}}$ optical density at $600 \mathrm{~nm}$, and cellobiose concentration versus time. Each data point represents the mean of five independent experiments and the error bar indicates the standard deviation.

Table 4 Comparison of growth and biomass yield of $Y$. lipolytica JMY1212 control and recombinant strains in aerobic cellobiose cultivation on defined medium

\begin{tabular}{lllll}
\hline Parameter & Control & ZetaB 1 & ZetaB 2 & ZetaB 12 \\
\hline $\begin{array}{l}\mu_{\max }\left(\mathrm{h}^{-1}\right) \text { on } \\
\text { glucose }\end{array}$ & $0.15 \pm 0.01$ & $0.16 \pm 0.01$ & $0.16 \pm 0.01$ & $0.16 \pm 0.01$ \\
$\begin{array}{l}\mu_{\max }\left(\mathrm{h}^{-1}\right) \text { on } \\
\text { cellobiose }\end{array}$ & NA & $0.09 \pm 0.01$ & $0.14 \pm 0.01$ & $0.15 \pm 0.01$ \\
$\begin{array}{l}Y_{\text {X/s }}(\mathrm{DCW} \text {-g/g cello) } \\
\text { Residue cellobiose } \\
60 \mathrm{~h}(\%)\end{array}$ & $\mathrm{NA}$ & $0.52 \pm 0.01$ & $0.53 \pm 0.01$ & $0.50 \pm 0.01$ \\
\hline
\end{tabular}

\pm , the standard deviation.

$N A$ not available.

one of these (SfBgl1) actually hydrolyzes $\beta-1,4$ glycosidic bonds [41]. In this respect it is also intriguing to note that while Bgl1 (described herein) displays good activity on both cellobiose and cellodextrin, its homolog from $S$. fibuligera (SfBgl2, 49.5\% identity) is inactive on cellobiose. Regarding the remaining four putative $\beta$-glucosidases, at this stage it is unclear why no recombinant products were revealed by western blot analysis. To pursue this further it would no doubt be useful to take a closer look at transcription, but this was not performed since the successful expression of two BGLs was more than enough to continue the present study.

The multiplicity of $\beta$-glucosidases in filamentous fungi is common and is often due to the presence of multiple genes, or differential post transcriptional modifications $[42,43]$. However, our study provides the first evidence of possible $\beta$-glucosidase multiplicity in yeast. In filamentous fungi, the apparent redundancy of multiple cellulolytic enzymes can be explained by the ability of these microorganisms to adapt to different biomass resources and culture conditions [43] and is probably essential in fungal metabolism and survival. Similarly, in the case of $Y$. lipolytica, the presence of multiple putative $\beta$-glycosidase genes (two of which have been shown to be $\beta$-glucosidases) could be the result of adaptation of the yeast to changing environments and may help to explain the different evolutionary history of this yeast. 

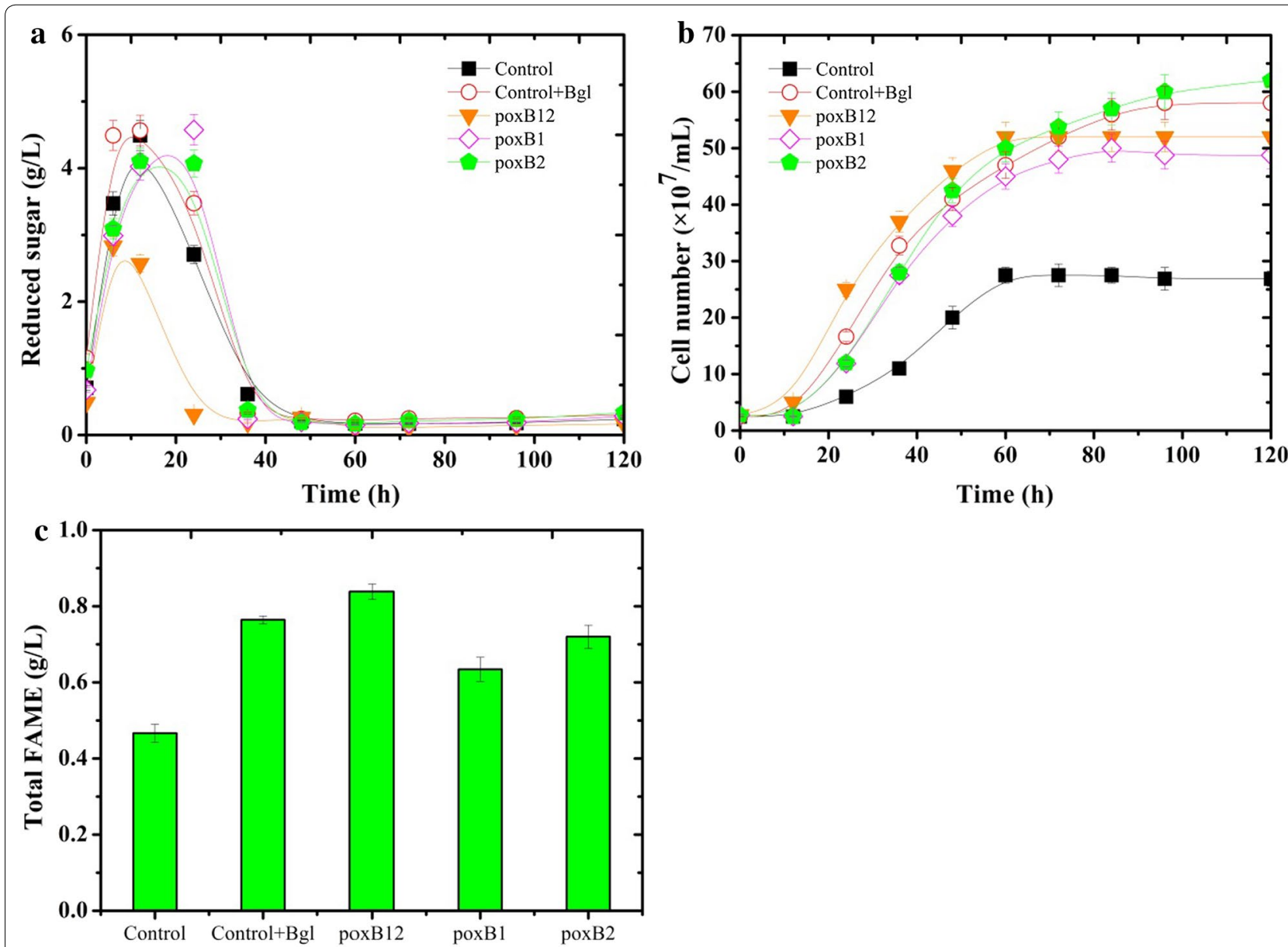

Fig. 7 Growth and lipid production on cellulose medium of Y. lipolytica strains. Growth during SSF on $50 \mathrm{~g} / \mathrm{L}$ cellulose supplemented with Celluclast 1.5L. a the concentration of reduced sugar versus time; $\mathbf{b}$ growth expressed as cell number versus time; $\mathbf{c}$ lipid content at $60 \mathrm{~h}$. Strains are $Y$. lipolytica $\triangle$ poxB1 $\left(P_{\text {TEF }}-B G L 1\right), \Delta$ poxB2 $\left(P_{\text {TEF }}-B G L 2\right), \Delta$ poxB12 $\left(P_{\text {TEF }}-B G L 1, P_{\text {TEF }}-B G L 2\right)$ and $\Delta$ poxW (wild type) under the same condition without (control) or with (control $+\mathrm{Bgl}$ ) extra $\beta$-glucosidase (Novozyme 188). Each data point represents the mean of at least three independent experiments and the error bars indicate the standard deviation.

Considering the physicochemical characteristics of the two Y. lipolytica $\beta$-glucosidases described in this study, it is possible to tentatively correlate these with the cellular localization of the enzymes. Bgl2 was more stable in the assay conditions employed $\left(50^{\circ} \mathrm{C}, \mathrm{pH} 4.0\right)$, which might arguably be logical for an extracellular enzyme that needs to show a certain resilience to environmental challenges. On the other hand, the relative fragility of Bgl1 can be explained by the fact that its natural intracellular location probably protects it from major temperature and $\mathrm{pH}$ changes. In this respect the different cellular locations of the enzymes is no doubt beneficial to the yeast, since it provides optimal activity.

The comparison of the specific activities of Bgll and Bgl 2 on cellobiose (108 units/mg and 25 units/mg protein, respectively) with that of the commercially available $\beta$-glucosidase from Aspergillus niger (5.2 units/mg protein), the enzyme that is generally used to complement the cellulolytic cocktail of $T$. reesei [44], is rather flattering for the former. Moreover, the $K_{\mathrm{M}}$ values describing the cellobiolytic reactions catalyzed by Bgl1 and 2 are approximately 10 and 3.4-fold lower than those of the $\beta$-glucosidases from $S$. fibuligera $(2.8 \mathrm{mM} \mathrm{Bgl1})$ and A. niger $(2.7 \mathrm{mM})$ [44], meaning that the minimum concentration of cellobiose required for effective catalysis to occur is much lower. Likewise, comparing the apparent performance constants, $k_{\mathrm{cat}} / K_{\mathrm{M}}$, of Y. lipolytica Bgls with those of other reported $\beta$-glucosidases [36-41, 44] suggests that the enzymes described in this study hydrolyze cellodextrins more efficiently. In this respect, it is also interesting to consider the fact that Bgl1 apparently exhibits higher catalytic performance on low DP 
cellodextrins, while $\mathrm{Bgl} 2$ is more active on higher DP ones. This difference in substrate preference is consistent with the cellular location of the two enzymes (i.e. the extracellular enzymes deals with the longer oligosaccharides that cannot be transported into the cell) and possibly forms the basis of the superior performance of ZetaB 12 on Avicel compared to control cultures containing the $\beta$-glucosidase from Novozymes 188.

Apparently, in the lipid production experiments performed in this study, the activity of the Yarrowia $\beta$-glucosidases adequately satisfied the requirements for exo-cellulase activity, since no accumulation of reducing sugars was observed. However, lipid production was not sustained, since growth ceased before the cellulose was consumed. This failure suggests that cellulose degradation was the limiting factor, with a part of the cellulose being recalcitrant to further hydrolysis by the Celluclast cocktail, even when Bgl1 and 2 were correctly expressed and thus available.

\section{Conclusions}

This study has provided a clear demonstration that $Y$. lipolytica does not naturally use cellobiose, despite the fact that this strain contains the genetic potential to do so. This is intriguing because the protein products of these genes are active on glucose-based oligosaccharides, including cello-oligosaccharides. Moreover, our data clearly show that upon expression of BGL1 and $B G L 2$ under the control of the constitutive well characterized TEF promoter in Y. lipolytica, growth on cellobiose becomes possible. These encouraging findings render plausible the creation of an engineered Y. lipolytica strain that could be useful in advanced generation biorefinery schemes involving the use of lignocellulosic hydrolysates as feedstock for the production of bioenergy and valuable chemicals.

\section{Methods}

\section{Strains and media}

The genotypes of the microbial strains used in the present study are summarized in Table 5 . E. coli DH5 were purchased from Invitrogen (Paisley, UK) and used for plasmid construction. The $Y$. lipolytica strains were routinely grown in YPD (1\% yeast extract, $2 \%$ bacto peptone, and $2 \%$ glucose). Solid YPD medium contains $1.5 \%$ agar. Transformants were selected on solid YNB medium $(0.17 \% \mathrm{w} / \mathrm{v}$ YNB, $1 \%$ glucose or cellobiose $\mathrm{w} / \mathrm{v}$, $0.5 \% \mathrm{w} / \mathrm{v}$ ammonium chloride, with (for $\mathrm{Ura}^{+}$) or without (for $\mathrm{Leu}^{+}$) $0.2 \% \mathrm{w} / \mathrm{v}$ casamino acids and $50 \mathrm{mM}$ sodium-potassium phosphate buffer, $\mathrm{pH}$ 6.8), supplemented with uracil $(440 \mathrm{mg} / \mathrm{L})$ or leucine $(440 \mathrm{mg} / \mathrm{L})$ depending on the auxotrophic requirements. The detection of $\beta$-glucosidase activity in solid YNBcasa medium was achieved by incorporating $1.0 \mathrm{mM} p$-nitrophenyl$\beta$-D-glucoside ( $p$ NP- $\beta$ Glc) [45]. For $\beta$-glucosidase characterization, enzymes were produced in YTD medium $(1 \% \mathrm{w} / \mathrm{v}$ yeast extract, $2 \% \mathrm{w} / \mathrm{v}$ tryptone, $5 \% \mathrm{w} / \mathrm{v}$ glucose and $100 \mathrm{mM}$ phosphate buffer, $\mathrm{pH}$ 6.8). To compare the efficiency of recombinant $\beta$-glucosidase to degrade cellobiose and cellodextrin with respect to cell growth, yeasts were aerobically cultivated in YNBcasa medium, containing $5 \mathrm{~g} / \mathrm{L}$ cellobiose or cello-oligosaccharides (C3-C6), and defined medium containing vitamins, trace elements [46] and salts, including $3.5 \mathrm{~g} / \mathrm{L}\left(\mathrm{NH}_{4}\right)_{2} \mathrm{SO}_{4}, 3.0 \mathrm{~g} / \mathrm{L}$ $\mathrm{K}_{2} \mathrm{HPO}_{4}, 3.0 \mathrm{~g} / \mathrm{L} \mathrm{NaH} \mathrm{PO}_{4}$ and $1.0 \mathrm{~g} / \mathrm{L} \mathrm{MgSO} \mathrm{Mg}_{4} \cdot 7 \mathrm{H}_{2} \mathrm{O}$ with $10 \mathrm{~g} / \mathrm{L}$ cellobiose. For lipid production using cellulose as the carbon source, $Y$. lipolytica strains were grown in defined media supplemented with $50 \mathrm{~g} / \mathrm{L}$ Avicel $\mathrm{PH}-101$.

\section{Plasmid constructions}

The plasmids constructed in the present study are summarized in Table 6, and all primers are listed in Table 7.

Table 5 Microbial strains used in the present study

\begin{tabular}{|c|c|c|}
\hline Strains & Relevant genotype & Source of reference \\
\hline E. coli DH5 & $\begin{array}{l}\text { Ф80dlacZ } \Delta \mathrm{m} 15 \text {, recA1, endA1, gyrA96, thi-1, hsdR17 }\left(\mathrm{rk}^{-}, \mathrm{mk}^{+}\right) \text {, } \\
\text { supE44, relA1, deoR, } \Delta \text { (lacZYA-argF) U169 }\end{array}$ & Invitrogen \\
\hline Y. lipolytica JMY1212 (Zeta) & 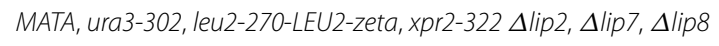 & {$[50]$} \\
\hline Y. lipolytica $\Delta$ pox JMY1233 & MATA, leu2-270, ura3-302, xpr2-322, pox1-6s & {$[29]$} \\
\hline ZetaW & MATA, xpr2-322, $\Delta$ lip2, $\Delta$ lip7, $\Delta$ lip8 & This investigation \\
\hline ZetaB 1 & $P_{\text {TEF }}-B G L 1$ & This investigation \\
\hline ZetaB 2 & $P_{T E F}-B G L 2$ & This investigation \\
\hline ZetaB 12 & $P_{T E F}-B G L 1, P_{T E F}-B G L 2$ & This investigation \\
\hline$\Delta p o x W$ & MATA, xpr2-322, pox1-6 $\Delta$ & This investigation \\
\hline$\Delta p o x B 1$ & $P_{T E F}-B G L 1$ & This investigation \\
\hline$\Delta p o x \mathrm{~B} 2$ & $P_{T E F}-B G L 2$ & This investigation \\
\hline$\Delta p o x B 12$ & $P_{T E F}-B G L 1, P_{T E F}-B G L 2$ & This investigation \\
\hline
\end{tabular}


Table 6 Plasmids used or created in the present study

\begin{tabular}{lll}
\hline Plasmids & Description & Source of reference \\
\hline JMP62UraTEF & $U R A 3, T E F_{P}-X P R_{T}$ & {$[56]$} \\
JMP62LeuTEF & $L E U 2, T E F_{P}-X P R_{T}$ & {$[57]$} \\
JMP62UraTB1 & $U R A 3, T E F_{P}-B G L 1-X P R_{T}$ & This investigation \\
JMP62UraTB2 & $U R A 3, T E F_{P}-B G L 2-X P R_{T}$ & This investigation \\
JMP62LeuTB2 & $\angle E U 2, T E F_{P}-B G L 2-X P R_{T}$ & This investigation \\
JMP62UraTB12 & $U R A 3, T E F_{P}-B G L 1-X P R_{T}, T E F_{P}-B G L 2-$ & This investigation \\
& $X P R_{T}$ & \\
\hline
\end{tabular}

The plasmids used for expression of the putative $\beta$-glucosidases were constructed using the expression vectors JMP62UraTEF and JMP62LeuTEF, which are derivatives of a previously described vector [47]. Briefly, these vectors contain the $Y$. lipolytica TEF promoter and either the URA3ex or LEU2ex excisable selection markers, which are flanked by loxP sites and a Zeta fragment that serves as the homologous integration site [48]. Regarding $\beta$-glucosidases, six putative gene candidates (Sequences YALIOF16027g, YALIOF01672g, YALIOD18381g, YALIOB14289g, YALIOB14333g, YALIOE20185g available at Genome Resources from Yeast Chromosomes: http:// gryc.inra.fr/) were identified (see Additional file 1: Table S1). For the expression of wild-type and His6-tagged proteins, the genes were amplified by PCR using FA (1-6) as forward primers and RB (1-6) or RB-His (1-6) as reverse primers, respectively. The PCR fragments were digested using either BamHI/AvrII or HindIII/AvrII and inserted into the plasmid JMP62 UraTEF at the corresponding sites.

After construction, all expression vectors were verified by DNA sequencing (GATC Biotech, Konstanz, Germany). For Y. lipolytica transformation, vectors were digested using NotI, thus generating a linear DNA with Zeta sequences at both extremities, and purified. Then the linear DNA fragments were introduced into the Zeta docking platform of Y. lipolytica JMY1212 Zeta or randomly into the genome of $\Delta p o x$ strain using the lithium acetate method [49]. Transformants were tested for $\beta$-glucosidase activity on YNB glucose plate containing $p$ NP- $\beta$ Glc and for growth on cellobiose using solid YNB cellobiose plates. Clones displaying both activities were retained for further analysis.

\section{Transcriptional analysis}

$Y$. lipolytica JMY1212 wide type and recombinant strains overexpressing BGL1 and BGL2 were grown to midexponential phase in defined media and then transferred into fresh medium containing either glucose or cellobiose as the sole carbon source. Cells were recovered from the medium at $20 \mathrm{~min}$ and $1 \mathrm{~h}$, respectively, and rapidly frozen in liquid nitrogen and stored at $-80^{\circ} \mathrm{C}$ until use. Total mRNA was isolated using RNeasy Plus Mini Kit (QIAGEN) and reverse transcription was performed with iScript ${ }^{\mathrm{TM}}$ cDNA Synthesis Kit (BIO-RAD) according

Table 7 The sequences of the oligonucleotide primers used in this study

\begin{tabular}{|c|c|c|}
\hline Primer names & Sequence $\left(5^{\prime}-3^{\prime}\right)$ restriction sites are italic/underlined & Restriction sites \\
\hline FA1 & 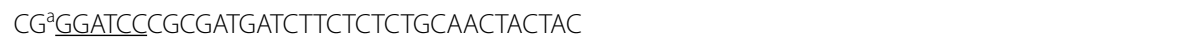 & BamHI \\
\hline RB1 & CGCCTAGGCTACAAAGTGAAAGTCTCACATAGC & Avrll \\
\hline FA2 & CCCAAGCTTGGGTTTGGAGGGGGTGAAAAA & HindllI \\
\hline RB2 & CCCAAGCTTGGGCTAAAGACCTAACCAATTCTTAGTCT & HindllI \\
\hline FA3 & CGGGATCCCGCGATGATTGCAAAAATACCCC & BamHI \\
\hline RB3 & CGCCTAGGCTACTGGAGAGTAAAGGACTCG & Avrll \\
\hline FA4 & CGGGATCCCGCGATGCTCGCATTCGTCCTAC & $\mathrm{BamHI}$ \\
\hline RB4 & CGGGATCCCGCTACTTGAGAGTGAAGCTGGTG & BamHI \\
\hline FA5 & CGGGATCCCGCGATGGCTCCACCCCCGCCTCCT & $\mathrm{BamHI}$ \\
\hline RB5 & CGCCTAGGTTAAGCAATCGTGATGCGACCAAGG & Avrll \\
\hline FA6 & CGCCTAGGCGCGATGGAGGAATTATCGGAGGC & Avrll \\
\hline RB6 & CGCCTAGGCTACCGGCTGAACTTCTCTTC & Avrll \\
\hline RB-His1 & ${ }^{\mathrm{b}}$ CGCCTAGGTTAATGATGGTGATGATGGTGGCTGCCGCGCGGCACCAGCCTAGGCAAAGTGAAAGTCTCA & \\
\hline RB-His2 & CCCAAGCTTGGGTTAATGATGGTGATGATGGTGGCTGCCGCGCGGCACCAGCCTAGGAAGACCTAACCAATTCTTA & \\
\hline RB-His3 & CGCCTAGGTTAATGATGGTGATGATGGTGGCTGCCGCGCGGCACCAGCCTAGGCTGGAGAGTAAAGGA & \\
\hline RB-His4 & CGGGATCCCGTTAATGATGGTGATGATGGTGGCTGCCGCGCGGCACCAGCCTAGGCTTGAGAGTGAAGCT & \\
\hline RB-His5 & CGCCTAGGTTAATGATGGTGATGATGGTGGCTGCCGCGCGGCACCAGCCTAGGAGCAATCGTGATGC & \\
\hline RB-His6 & CGCCTAGGTTAATGATGGTGATGATGGTGGCTGCCGCGCGGCACCAGCCTAGGCTGAACTTCTCTTCC & \\
\hline
\end{tabular}


to the manufacturer's instructions. Transcription of the $B G L s$ was analyzed by PCR, using gene-specific primers and sequencing of the PCR products (Additional file 1: Table S3).

\section{Measurement of enzyme activity}

$\beta$-Glucosidase activity was measured by quantifying the release of $p \mathrm{NP}$ ( $p$-nitrophenol) from $p$ NP- $\beta$ Glc as described previously [50]. One unit of $p \mathrm{NP}-\beta$ Glcase activity was defined as the amount of enzyme required to release $1 \mu \mathrm{mol} p \mathrm{NP}$ per min. All protein concentrations were measured using the Bradford method and bovine serum albumin as a standard [47].

\section{Western blot analysis}

Western blotting of proteins was performed as described previously [51]. Crude supernatant and cell-free extracts of $Y$. lipolytica JMY1212 expressing putative $\beta$-glucosidases fused with the His6 tag were concentrated 10-fold using an ultra-centrifugation filter unit (Amicon ${ }^{\circledR}$ Ultra-4 $10 \mathrm{kDa}$ cut-off, Merk Millipore, Bedford, MA, USA). Blots were sequentially treated with mouse non position-specific HisTag antibody 1:2,500 (THE $^{\mathrm{TM}}$ from Genscript, Piscataway, NJ, USA) and the alkaline phosphatase-conjugated goat anti-mouse IgG.

\section{Subcellular fractionation and enzyme localization}

Fractionation of yeast cells was carried out as described by Cummings and Fowler [52], with slight modifications. Briefly, yeasts were cultivated until a cellular density of $6 \times 10^{7}$ cells $/ \mathrm{mL}$ was reached. Then, to quantify total $\beta$-glucosidase activity, a $50-\mathrm{mL}$ sample was taken and subjected to centrifugation at $8,000 \times g$ for $5 \mathrm{~min}$ at $4^{\circ} \mathrm{C}$ thus isolating a cell pellet and supernatant. The cell pellet was disrupted in Tris- $\mathrm{HCl}$ buffer $(50 \mathrm{mM}, \mathrm{pH} 7.4$, $3 \mathrm{mM}$ EDTA and $0.5 \mathrm{mM}$ PMSF) using a MP FastPrep-24 Instrument (MP Biomedicals Inc.). $\beta$-Glucosidase activity in both the cell lysate and the supernatant was determined as described earlier to estimate total $\beta$-glucosidase activity. Using a second $50 \mathrm{~mL}$ yeast culture, a cell pellet containing approximately $2 \times 10^{8}$ cells $/ \mathrm{mL}$ was obtained by centrifugation and then treated with zymolyase $100 \mathrm{~T}$ at $10 \mathrm{mg} / \mathrm{mL}$ (Seikagaku corp coger) in $15 \mathrm{~mL}$ of sorbitol buffer (1 M sorbitol, $50 \mathrm{mM}$ Tris-HCl, $\mathrm{pH}$ 7.4, $2 \mathrm{mM}$ dithiothreitol, $10 \mathrm{mM} \mathrm{MgCl}, 20 \mathrm{mM}$-sodium azide, $0.5 \mathrm{mM} \mathrm{PMSF}$ ) at $30^{\circ} \mathrm{C}$ with gentle shaking. Protoplast formation was monitored using a microscope until $\geq 99 \%$ of the cells was lysed when SDS was added ( $1 \%$ SDS w/v). The solid protoplast fraction was then separated from the supernatant by centrifugation $(1,000 \mathrm{rpm}$ for $5 \mathrm{~min}$ at $4^{\circ} \mathrm{C}$ ) and the latter was designated as the periplasmic fraction. The protoplasts were re-suspended in Tris$\mathrm{HCl}$ buffer ( $50 \mathrm{mM}$ Tris- $\mathrm{HCl}, \mathrm{pH} 7.4)$ and disrupted by vortex in the presence of glass beads $(0.4-0.45 \mathrm{~mm})$. The homogenate was centrifuged $\left(20,000 \times g\right.$ for $2 \mathrm{~h}$ at $\left.4^{\circ} \mathrm{C}\right)$ and the supernatant and solid fractions were designated as the cytoplasmic and membrane fraction, respectively. Prior to enzyme assays, the membrane fraction was suspended in citrate buffer.

\section{Purification of $\beta$-glucosidases}

Y. lipolytica JMY1212 overproducing Bgl1-His6 and Bgl2 was grown in $200 \mathrm{~mL} \mathrm{YTD} \mathrm{medium} \mathrm{at} 130 \mathrm{rpm}, 28^{\circ} \mathrm{C}$ for $36 \mathrm{~h}$ before centrifugation at $8,000 \times g$ for $5 \mathrm{~min}$. For purification of His6-Bgl1, the cell pellet was washed, suspended in $50 \mathrm{~mL}$ phosphate buffer ( $50 \mathrm{mM}, \mathrm{pH} 7.4$ ) and homogenized over a 3-min period using a MP FastPrep-24 Instrument. After centrifugation $(8,000 \times \mathrm{g}$ for $5 \mathrm{~min}$ at $4^{\circ} \mathrm{C}$ ), the supernatant was applied to $2 \mathrm{~mL}$ of TALON Metal Affinity Resin (Clontech, Takara-Bio, Kyoto, Japan) and protein was eluted using imidazole buffer according to the manufacturer's instructions.

For purification of Bgl2, the culture supernatant was concentrated fivefold using an Amicon ${ }^{\circledR}$ Ultra-4 Centrifugal Filter Unit with $30 \mathrm{kDa}$ cut-off (Merk Millipore, Bedford, MA, USA). The concentrated sample was then loaded onto a Q Sepharose ${ }^{\mathrm{TM}}$ High Performance column (Hiload, $1.6 \times 10 \mathrm{~cm}$, Pharmacia Biotech), equilibrated with Tris-buffer $(20 \mathrm{mM}, \mathrm{pH} 8.0)$. The column was washed first with equilibration buffer ( 2 bed volumes) before applying a linear gradient of $0-1.0 \mathrm{M} \mathrm{NaCl}$ in Tris-buffer $(20 \mathrm{mM}, \mathrm{pH} 7.4)$ at a flow rate of $1.0 \mathrm{~mL} /$ min (Pharmacia Biotech ÄKTA). Eluted fractions were collected and assayed for $\beta$-glucosidase activity. All fractions displaying activity were pooled, desalted and concentrated using an Amicon ultra-filtration unit equipped with a PM-10 membrane (Millipore), before being applied to a Superdex 200 column $(1.0 \times 30 \mathrm{~cm}$, Pharmacia Biotech) equilibrated in Tris-sodium buffer $(20 \mathrm{mM}$ Tris- $\mathrm{HCl}, 150 \mathrm{mM} \mathrm{NaCl}, \mathrm{pH}$ 7.4). Protein species were separated at a flow rate of $0.5 \mathrm{~mL} / \mathrm{min}$. Fractions were collected and analyzed by SDS-PAGE to ascertain purity and estimate the approximate molecular weights of Bgl1His6 and Bgl2. All fractions satisfying the purity criterion ( $>95 \%$ purity) were pooled and retained for further work.

\section{Deglycosylation and $\mathrm{N}$-terminal amino acid sequencing}

Purified Bgl1-His6 and Bgl2 were treated with endoglycosidase H (New England Biolabs, Beverly, MA, USA) according to the manufacturer's instructions. After deglycosylation, the protein species displaying $M_{r}$ (relative molecular mass) closest to those of the theoretical $M_{r}$ (predicted using Protparam, http://web.expasy.org/ protparam/) of Bgl1-His6 and Bgl2 were excised and submitted to N-terminal amino acid sequencing (PISSARO platform, Rouen, France). 


\section{Physicochemical characteristics of $\beta$-glucosidases}

Optimal temperatures and $\mathrm{pH}$ for the activity of Bgl1 and $\mathrm{Bgl} 2$ were determined using $p$ NPGlc as the substrate. Assays were either performed at $\mathrm{pH} 5.0$ and various temperatures $\left(30-70^{\circ} \mathrm{C}\right)$ or at $30^{\circ} \mathrm{C}$ in variable $\mathrm{pH}$ conditions (2.0-8.0) using either $50 \mathrm{mM}$ glycine- $\mathrm{HCl}$ ( $\mathrm{pH} 2.0), 50 \mathrm{mM}$ citrate/acetate $(\mathrm{pH} 3.0-7.2)$ or potassium phosphate (pH 7.0-8.2) buffer. When the temperature was varied, the $\mathrm{pH}$ of the citrate buffer was adjusted accordingly. Stability of Bgl1 and Bgl2 depending on $\mathrm{pH}$ and temperature was analyzed as follows: enzymes were incubated at $30^{\circ} \mathrm{C}$ for up to $2 \mathrm{~h}$ at various $\mathrm{pH}$ values $(2.0-$ 8.0) or at various temperatures $\left(30-70^{\circ} \mathrm{C}\right)$ for up to $2 \mathrm{~h}$ in $50 \mathrm{mM}$ citrate buffer, $\mathrm{pH}$ 5.0. Residual glucosidase activity was then assayed at $30^{\circ} \mathrm{C}$ in $50 \mathrm{mM}$ citrate buffer, $\mathrm{pH}$ 5.0.

\section{Substrate specificity and enzyme kinetics}

The substrate specificity of Bgl1-His6 and Bgl2 was investigated by assaying for activity on the aryl-glycosides $p \mathrm{NP}-\beta$-D-glucopyranoside, $\quad p \mathrm{NP}-\alpha$-D-glucopyranoside, $p$ NP- $\beta$-D-galactopyranoside, $\quad$ pNP- $\beta$-D-xylopyranoside and pNP- $\beta$-D-cellobioside, and on the oligosaccharides cellobiose, cellotriose, cellotetraose, cellopentaose, cellohexaose, sophorose, laminaribiose, gentiobiose, methylglucoside and octylglucoside. When using arylsubstrates, the standard assay method was employed, simply replacing $p$ NP- $\beta$ Glc by another substrate as appropriate. For oligosaccharides, the release of glucose was quantified using an enzyme kit (D-Fructose/DGlucose Assay Kit, liquid stable, Megazyme). To study the Michaelis-Menten parameters $K_{\mathrm{M}}, V_{\max }$ and $k_{\text {cat }}$, Bgl1 $(0.120 \mathrm{nM})$ or Bgl2 $(0.13 \mathrm{nM})$ were added to reaction mixtures containing different substrate concentrations: $0.25-5 \mathrm{mM}$ cellobiose, $0.25-5 \mathrm{mM}$ cellotriose, $0.25-5 \mathrm{mM}$ cellotetraose, $0.25-5 \mathrm{mM}$ cellopentaose, $0.25-5 \mathrm{mM}$ cellohexaose, $0.2-4 \mathrm{mM}$ sophorose, 0.1-2 mM laminaribiose, 0.1-2 $\mathrm{mM}$ gentiobiose, 0.5$20 \mathrm{mM}$ methylglucoside and $0.2-4 \mathrm{mM}$ octylglucoside. Initial rates were fitted to the Michaelis-Menten kinetic equation using a nonlinear regression (SigmaPlot 10) to extract the apparent $K_{\mathrm{M}}$ and $k_{\text {cat }}$ [53].

\section{Yeast growth and lipid production}

Yeast growth on cellobiose and cellodextrins was performed in a 40-well microplate. A single colony from a fresh YPD plate was transferred into $5 \mathrm{~mL}$ of defined medium containing $10 \mathrm{~g} / \mathrm{L}$ of glucose and pre-cultured until the mid-exponential phase. The cells were then harvested, washed, suspended in sterile water and used to inoculate $200 \mu \mathrm{L}$ YNBcasa media containing $5 \mathrm{~g} / \mathrm{L}$ cellobiose or cellodextrins in the microplate, achieving an initial $\mathrm{OD}_{600}$ of 0.1 . This culture was grown in a microplate reader (Spectrostar Omega, BMG Labtech, Germany) at $30^{\circ} \mathrm{C}$ with continuous shaking (150 rpm) and automatic $\mathrm{OD}_{600}$ recording. Similarly, yeast growth on cellobiose was also performed on $30 \mathrm{ml}$ defined medium containing $10 \mathrm{~g} / \mathrm{L}$ cellobiose in $250 \mathrm{~mL}$ Erlenmeyer flasks.

For lipid production a fresh yeast culture in exponential phase was used to inoculate $50 \mathrm{~mL}$ defined medium containing $50 \mathrm{~g} / \mathrm{L}$ Avicel in Erlenmeyer flasks, achieving an initial $\mathrm{OD}_{600}$ of 1.0. Celluclast 1.5L $(60 \mathrm{FPU} / \mathrm{mL}$, gift from Novozymes, Denmark) was added $(7.5 \mathrm{U} / \mathrm{g}$ cellulose) and growth was pursued for 5 days $\left(30^{\circ} \mathrm{C}, 150 \mathrm{rpm}\right)$. Samples were taken at regular intervals to determine concentrations of biomass, glucose, cellobiose and citric acid. In parallel, two control experiments were conducted under the same conditions, with or without the addition of extra $\beta$-glucosidase $(810 \mathrm{IU} / \mathrm{mL}$ Novozyme 188, gift from Novozyme, Denmark) at $12.0 \mathrm{IU} / \mathrm{g}$ cellulose as recommended [54].

\section{Analysis of product formation and determination of dry cell weight}

To determine the concentration of substrates and extracellular metabolites, three aliquots $(1.5 \mathrm{~mL}$ each) of cultures were rapidly frozen in liquid nitrogen and then thawed on ice before centrifugation $(8,000 \times g$ for $5 \mathrm{~min}$ at $4^{\circ} \mathrm{C}$ ) to recover supernatants for analysis. Glucose, cellobiose and citric acid were measured using an Aminex HPX87-H column (Bio-Rad Laboratories, Germany), operating at $50^{\circ} \mathrm{C}$ using a mobile phase $\left(5 \mathrm{mM} \mathrm{H}_{2} \mathrm{SO}_{4}\right)$ flowing at a rate of $0.5 \mathrm{~mL} / \mathrm{min}$. Glucose and cellobiose were detected using a Shodex RI-101 refractive index detector (Showa Denko, New York, NY, USA), while citric acid was detected using an UV detector at $210 \mathrm{~nm}$ (Dionex, Sunnyvale, CA, USA).

To determine the dry cell weight, three aliquots $(5 \mathrm{~mL}$ each) of cultures were filtered through pre-weighed PES filters $(0.45 \mu \mathrm{m}$; Sartorius Biolab, Germany). The biomass retained by the filters was washed, dried in a microwave oven at $150 \mathrm{~W}$ for $15 \mathrm{~min}$ and then placed in a desiccator before weighing. The biomass yield was calculated as the ratio of the amount of biomass obtained divided by the amount of carbon source consumed.

Lipids were extracted from freeze-dried cells $(\sim 10 \mathrm{mg})$ and methylated as described previously [55]. During the lipid extraction, C17:0 (Sigma) $(50 \mu \mathrm{g})$ was added as the internal standard and fatty acid methyl esters (FAMEs) were analyzed by gas chromatography (6890 N Network GC System, Agilent, USA). The measurements were performed in a split mode $\left(1 \mu \mathrm{L}\right.$ at $\left.250^{\circ} \mathrm{C}\right)$, with helium as the carrier gas $(2 \mathrm{~mL} / \mathrm{min})$. FAMEs were separated on a HP-5 GC column $(30 \mathrm{~m} \times 0.32 \mathrm{~mm}$ I.D., $0.5-\mu \mathrm{m}$ film thickness, Agilent, USA). The temperature program was $120^{\circ} \mathrm{C}$, ramped to $180^{\circ} \mathrm{C}\left(10^{\circ} \mathrm{C} / \mathrm{min}\right)$ for $6 \mathrm{~min}, 183^{\circ} \mathrm{C}$ 
$\left(0.33^{\circ} \mathrm{C} / \mathrm{min}\right)$ for $9 \mathrm{~min}$ and $250^{\circ} \mathrm{C}\left(15^{\circ} \mathrm{C} / \mathrm{min}\right)$ for $5 \mathrm{~min}$. Detection was performed using a flame ionization detector (FID) at $270^{\circ} \mathrm{C}(2.0 \mathrm{pA})$. FAMEs were quantified by comparing their profiles with that of standards of known concentration.

\section{Additional files}

Additional file 1: Table S1. Six putative $\beta$-glucosidase coding genes identified harboring conserved glycosyl hydrolase family $3 \mathrm{~N}$ and/or $3 \mathrm{C}$ terminal domain. Table S2. The predicted $\mathrm{N}$-glycosylation sites in sequence of Bgl2 by GlycoEP. Table S3. The sequences of the oligonucleotide primers used in verification of transcriptions.

Additional file 2: Figure S1. Multiple alignments of putative conserved domains of the family 3 glycosyl hydrolases of S. fibuligera (Bgl1, GenBank Accession numbers: AAA34314.1) against Yarrowia genome. Figure S2. Screening of Y. lipolytica expressing the 6 putative $\beta$-glucosidases on (a) indication plate containing YNBcasa medium supplemented with $1 \mathrm{mM}$ $p$-nitrophenyl- $\beta$-D-glucoside ( $p N P-\beta G l c)$, and $(b, c)$ YNBC plate with cellobiose as sole carbon source. Figure S3. Transcriptional analysis of the expression of the six putative $B G L s$ in wild type strain on glucose (A) and cellobiose (B), and recombinant strain overexpression of $B G L 1$ and $B G L 2$ (C). Figure S4. $\mathrm{N}$-terminal amino acid sequences of Y. lipolytica Bgl1 (A) and Bgl2 (B). The first $50 \mathrm{~N}$-terminal amino acid sequences are indicated with the predicted signal sequence determined with signal $P$ (underlined), the cleavage site predicted with $\mathrm{a}^{*}$, and the $\mathrm{N}$-terminal AA sequence of the purified protein determined by direct sequencing (in bold). Figure S5. Optimal pH (a) and temperature (b) of Bgl1 (square) and Bgl2 (diamond) from Y. lipolytica JMY1212. Each data point represents the mean of three independent experiments and the error bar indicates the standard deviation. Figure S6. Stability of Bgl1 (a) and Bgl2 (b) from Y. lipolytica JMY1212 at pH from 2.0-8.0 as a function of time at $30^{\circ} \mathrm{C}$, and stability of $\mathrm{Bgl} 1$ (c) and $\mathrm{Bgl} 2$ (d) at temperature from $30^{\circ} \mathrm{C}$ to $60^{\circ} \mathrm{C}$ as a function of time at pH 5. Each data point represents the mean of three independent experiments and the error bar indicates the standard deviation. Please note that only one curve is given to represent the stability of $\mathrm{Bg} / 2$ at $\mathrm{pH}$ 4.0, 5.0 and 6.0 (b) and at $30^{\circ} \mathrm{C}$ and $40^{\circ} \mathrm{C}$ (d) as $100 \%$ of enzyme activity remained for these conditions. Figure S7. The hydrolytic activity of Bgl2 on $p N P-\beta G l c(a)$ and the stability of $\mathrm{Bg} / 2$ at $40^{\circ} \mathrm{C}$ as a function of time at pH5.0 before and after deglycosylation. Each data point represents the mean of three independent experiments and the error bar indicates the standard deviation.

\section{Abbreviations}

LC biomass: lignocellulosic biomass; CBP: consolidated bioprocessing; FAEE: fatty acid ethyl esters; SSF: simultaneous saccharification and fermentation; FAEs: Fatty Acid Esters; DCW: dry cell weight; SCO: single cell oil; FDA: Food and Drug Administration; GRAS: generally recognized as safe; $p N P-\beta G \mid c$ : $p$-nitrophenyl- $\beta$-D-glucoside; $M_{r}$ : relative molecular mass; $B g l: \beta$-glucosidase.

\section{Authors' contributions}

ZPG, SB, SD, JMN, AM, MJD conceived of the study and participated in its design. ZPG designed the constructs, carried out all the experiments and drafted the manuscript. SD participated in the western blot analysis of the expressed proteins. GC participated in the protein purification. SB, SD, JMN, AM, MJD revised the manuscript. All authors read and approved the final manuscript.

\section{Author details}

1 LISBP-Biocatalysis Group, INSA/INRA UMR 792, Université de Toulouse, 135 Avenue de Rangueil, 31077 Toulouse, France. ${ }^{2}$ INRA, UMR792 Ingénierie des Systèmes Biologiques et des Procédés, 31400 Toulouse, France. ${ }^{3}$ CNRS, UMR5504, 31400 Toulouse, France. ${ }^{4}$ INRA, UMR1319 Micalis, 78352 Jouy-en-Josas, France. ${ }^{5}$ AgroParisTech, UMR Micalis, 78352 Jouy-en-Josas, France.

\section{Acknowledgements}

The authors would like to express their gratitude to Nelly Monties for her help with chromatographic analyses. They thank the ICEO facility dedicated to enzyme screening and discovery and part of the Integrated Screening Platform of Toulouse (PICT, IBiSA) for providing access to its protein purification and analytical facilities. This work was funded by the Agence Nationale de la Recherche (Investissements d'Avenir program; reference ANR-11-BTBR-0003). Dr. Guo is a recipient of a postdoctoral fellowship from the Institut National de la Recherche Agronomique.

\section{Compliance with ethical guidelines}

\section{Competing interests}

The authors declare that they have no competing interests.

Received: 24 March 2015 Accepted: 22 July 2015

Published online: 04 August 2015

\section{References}

1. Pedersen M, Meyer AS (2010) Lignocellulose pretreatment severity-relating pH to biomatrix opening. N Biotechnol 27(6):739-750

2. Wilson DB (2009) Cellulases and biofuels. Curr Opin Biotechnol 20(3):295-299

3. Tomme P, Warren RA, Gilkes NR (1995) Cellulose hydrolysis by bacteria and fungi. Adv Microb Physiol 37:1-81

4. Sun Y, Cheng J (2002) Hydrolysis of lignocellulosic material for ethanol production: a review. Bioresour Technol 83:1-11

5. Lynd LR, van Zyl WH, McBride JE, Laser M (2005) Consolidated bioprocessing of cellulosic biomass: an update. Curr Opin Biotechnol 16:577-583

6. La Grange DC, Den Haan R, Van Zyl WH (2010) Engineering cellulolytic ability into bioprocessing organisms. Appl Microbiol Biotechnol 87:1195-1208

7. Duff SJB, Cooper DG, Fuller OM (1985) Cellulase and beta-glucosidase production by mixed culture of Trichoderma reesei Rut C 30 and Aspergillus phoenicis. Biotechnol Lett 7:185-190

8. Holtzapple M, Cognata M, Shu Y, Hendrickson C (1990) Inhibition of Trichoderma reesei cellulase by sugars and solvents. Biotechnol Bioeng 36(3):275-287

9. Stockton DC, Mitchell DJ, Grohmann K (1991) Optimum $\beta$-glucosidase supplementation of cellulose for efficient conversion of cellulose to glucose. Biotechnol Lett 13:57-62

10. Lee WH, Nan H, Kim HJ, Jin YS (2013) Simultaneous saccharification and fermentation by engineered Saccharomyces cerevisiae without supplementing extracellular $\beta$-glucosidase. J Biotechnol 167(3):316-322

11. Lian J, Li Y, HamediRad M, Zhao H (2014) Directed evolution of a cellodextrin transporter for improved biofuel production under anaerobic conditions in Saccharomyces cerevisiae. Biotechnol Bioeng 111(8):1521-1531

12. Tang H, Hou J, Shen Y, Xu L, Yang H, Fang X et al (2013) High $\beta$-glucosidase secretion in Saccharomyces cerevisiae improves the efficiency of cellulase hydrolysis and ethanol production in simultaneous saccharification and fermentation. J Microbiol Biotechnol 23(11):1577-1585

13. Zhang F, Carothers JM, Keasling JD (2012) Design of a dynamic sensorregulator system for production of chemicals and fuels derived from fatty acids. Nat Biotechnol 30(4):354-359

14. Demirbaş A (2003) Biodiesel fuels from vegetable oils via catalytic and non-catalytic supercritical alcohol transesterifications and other methods: a survey. Energy Convers Manage 44:2093-2109

15. Steen EJ, Kang Y, Bokinsky G, Hu Z, Schirmer A, McClure A et al (2010) Microbial production of fatty-acid-derived fuels and chemicals from plant biomass. Nature 463:559-562

16. Shi S, Octavio Valle-Rodriguez J, Khoomrung S, Siewers V, Nielsen J (2012) Functional expression and characterization of five wax ester synthases in Saccharomyces cerevisiae and their utility for biodiesel production. Biotechnol Biofuels 5:7-16

17. Runguphan W, Keasling JD (2014) Metabolic engineering of Saccharomyces cerevisiae for production of fatty acid-derived biofuels and chemicals. Metab Eng 21:103-113 
18. Nielsen J (2009) Systems biology of lipid metabolism: from yeast to human. FEBS Lett 583(24):3905-3913

19. Valle-Rodríguez JO, Shi S, Siewers V, Nielsen J (2014) Metabolic engineering of Saccharomyces cerevisiae for production of fatty acid ethyl esters, an advanced biofuel, by eliminating non-essential fatty acid utilization pathways. Appl Energ 115:226-232

20. Ratledge C (2005) Single cell oils for the 21 th century. In: Cohen R (ed) Single cell oils. AOCS Press, Champaign, pp 1-20

21. Thevenieau F, Nicaud J-M (2013) Microorganisms as sources of oils. OCL 20(6):1-8

22. Papanikolaou S, Aggelis G (2010) Yarrowia lipolytica: a model microorganism used for the production of tailor-made lipids. Eur J Lipid Sci Technol 112:639-654

23. Easterling ER, French WT, Hernandez R, Licha M (2009) The effect of glycerol as a sole and secondary substrate on the growth and fatty acid composition of Rhodotorula glutinis. Bioresour Technol 100(1):356-361

24. Blazeck J, Hill A, Liu L, Knight R, Miller J, Pan A et al (2014) Harnessing Yarrowia lipolytica lipogenesis to create a platform for lipid and biofuel production. Nat Commun 5:3131

25. Groenewald M, Boekhout T, Neuvéglise C, Gaillardin C, van Dijck PW, Wyss M (2014) Yarrowia lipolytica: safety assessment of an oleaginous yeast with a great industrial potential. Crit Rev Microbiol 40(3):187-206

26. Michely S, Gaillardin C, Nicaud J-M, Neuvéglise C (2013) Comparative physiology of oleaginous species from the Yarrowia clade. PLoS One 8(5):e63356

27. Lane S, Zhang S, Wei N, Rao C, Jin YS, Lee WH et al (2014) Development and physiological characterization of cellobiose-consuming Yarrowia lipolytica. Biotechnol Bioeng (In press)

28. Chauhan JS, Rao A, Raghava GPS (2013) In silico platform for prediction of $\mathrm{N}$-, O- and C-glycosites in eukaryotic protein sequences. PLoS One 8(6):e67008

29. Beopoulos A, Mrozova Z, Thevenieau F, Le Dall MT, Hapala I, Papanikolaou S et al (2008) Control of lipid accumulation in the yeast Yarrowia lipolytica. Appl Environ Microbiol 74(24):7779-7789

30. Singhania RR, Patel AK, Sukumaran RK, Larroche C, Pandey A (2013) Role and significance of beta-glucosidases in the hydrolysis of cellulose for bioethanol production. Bioresour Technol 127:500-507

31. Rodrigues AC, Leitão AF, Moreira S, Felby C, Gama M (2012) Recycling of cellulases in lignocellulosic hydrolysates using alkaline elution. Bioresour Technol 110:526-533

32. Jeon E, Hyeon JE, Suh DJ, Suh YW, Kim SW, Song KH et al (2009) Production of cellulosic ethanol in Saccharomyces cerevisiae heterologous expressing Clostridium thermocellum endoglucanase and Saccharomycopsis fibuligera beta-glucosidase genes. Mol Cell 28:369-373

33. Shen Y, Zhang Y, Ma T, Bao X, Du F, Zhuang G et al (2008) Simultaneous saccharification and fermentation of acid-pretreated corncobs with a recombinant Saccharomyces cerevisiae expressing beta-glucosidase. Bioresour Technol 99:5099-5103

34. Fickers P, Benetti P-H, Waché Y, Marty A, Mauersberger S, Smit M et al (2005) Hydrophobic substrate utilisation by the yeast Yarrowia lipolytica, and its potential applications. FEMS Yeast Res 5:527-543

35. Dujon B, Sherman D, Fischer G, Durrens P, Casaregola S, Lafontaine I et al (2004) Genome evolution in yeasts. Nature 430:35-44

36. Belancic A, Gunata Z, Vallier MJ, Agosin E (2003) $\beta$-Glucosidase from the grape native yeast Debaryomyces vanrijiae. Purification, characterization, and its effect on monoterpene content of a muscat grape juice. J Agric Food Chem 51:1453-1459

37. Galas E, Romanowska I (1996) Production purification and characterization of a highly glucose-tolerant novel ß-glucosidase from Candida peltata. Appl Environ Microbiol 62:3165-3170

38. Daroit DJ, Simonetti A, Hertz PF, Brandelli A (2008) Purification and characterization of an extracellular beta-glucosidase from Monascus purpureus. J Microbiol Biotechnol 18:933-941
39. Leclerc M, Chemardin P, Arnaud A, Ratomahenina R, Galzy P, Gerbaud C et al (1987) Comparison of the properties of the purified beta-glucosidase from the transformed strain of Saccharomyces cerevisiae TYKF2 with that of the donor strain Kluyveromyces fragilis Y610. Biotechnol Appl Biochem 9:410-422

40. González-Pombo P, Pérez G, Carrau F, Guisán JM, Batista-Viera F, Brena BM (2008) One-step purification and characterization of an intracellular beta-glucosidase from Metschnikowia pulcherrima. Biotechnol Lett 30:1469-1475

41. Machida M, Ohtsuki I, Fukui S, Yamashita I (1988) Nucleotide sequences of Saccharomycopsis fibuligera genes for extracellular beta-glucosidases as expressed in Saccharomyces cerevisiae. Appl Environ Microbiol 54(12):3147-3155

42. Collins T, Gerday C, Feller G (2005) Xylanases, xylanase families and extremophilic xylanases. FEMS Microbiol Rev 29:3-23

43. Nazir A, Soni R, Saini HS, Kaur A, Chadha BS (2010) Profiling differential expression of cellulases and metabolite footprints in Aspergillus terreus. Appl Biochem Biotechnol 162:538-547

44. Yan TR, Lin CL (1997) Purification and characterization of a glucose-tolerant $\beta$-glucosidase from Aspergillus niger CCRC 31494. Biosci Biotechnol Biochem 61:965-970

45. Guo ZP, Zhang L, Ding ZY, Gu ZH, Shi GY (2011) Development of an industrial ethanol-producing yeast strain for efficient utilization of cellobiose. Enzyme Microb Technol 49(1):105-112

46. Verduyn C, Postma E, Scheffers WA, van Dijken JP (1992) Effect of benzoic acid on metabolic fluxes in yeasts: a continuous culture study on the regulation of respiration and alcoholic fermentation. Yeast 8:501-517

47. Bradford MM (1976) A rapid and sensitive method for the quantitation of microgram quantities of protein utilizing the principle of protein-dye binding. Anal Biochem 72:248-254

48. Fickers P, Le Dall MT, Gaillardin C, Thonart P, Nicaud J-M (2003) New disruption cassettes for rapid gene disruption and marker rescue in the yeast Yarrowia lipolytica. J Microbiol Methods 55(3):727-737

49. Duquesne S, Bordes F, Fudalej F, Nicaud J-M, Marty A (2012) The yeast Yarrowia lipolytica as a generic tool for molecular evolution of enzymes. Methods Mol Biol 861:301-312

50. Bordes F, Fudalej F, Dossat V, Nicaud J-M, Marty A (2007) A new recombinant protein expression system for high-throughput screening in the yeast Yarrowia lipolytica. J Microbiol Methods 70(3):493-502

51. Duquesne S, Bozonnet S, Bordes F, Dumon C, Nicaud J-M, Marty A (2014) Construction of a highly active xylanase displaying oleaginous yeast: comparison of anchoring systems. PLoS One 9(4):e95128

52. Cummings C, Fowler T (1996) Secretion of Trichoderma reesei $\beta$-glucosidase by Saccharomyces cerevisiae. Curr Genet 29:227-233

53. Segel I (1993) Enzyme kinetics: behavior and analysis of rapid equilibrium and steady-state enzyme systems. John Wiley, New York

54. Lan TQ, Lou H, Zhu JY (2013) Enzymatic saccharification of lignocelluloses should be conducted at elevated $\mathrm{pH} 5.5$ to 6.2. Bioenergy Res 6((2):476-485

55. Browse J, McCourt PJ, Somerville CR (1986) Fatty acid composition of leaf lipids determined after combined digestion and fatty acid methyl ester formation from fresh tissue. Anal Biochem 152:141-145

56. Haddouche R, Poirier Y, Delessert S, Sabirova J, Pagot Y, Neuvéglise C et al (2011) Engineering polyhydroxyalkanoate content and monomer composition in the oleaginous yeast Yarrowia lipolytica by modifying the ß-oxidation multifunctional protein. Appl Microbiol Biotechnol 91(5):1327-1340

57. Nicaud J-M, Madzak C, van den Broek P, Gysler C, Duboc P, Niederberger P et al (2002) Protein expression and secretion in the yeast Yarrowia lipolytica. FEMS Yeast Res 2(3):371-379 